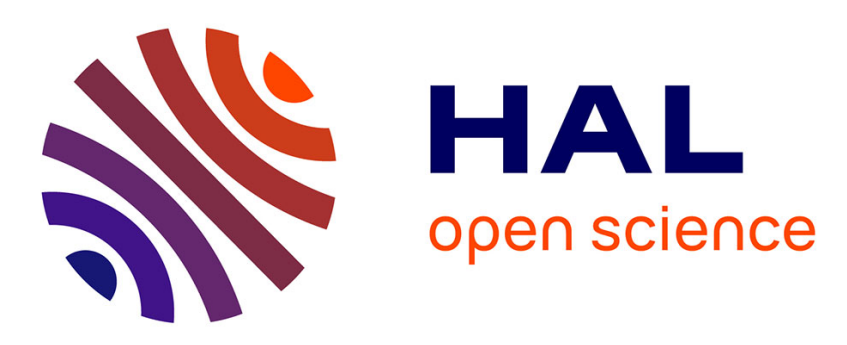

\title{
Evolution of life cycles and reproductive traits: insights from the brown algae
}

\author{
Svenja Heesch, Martha Serrano-serrano, Josué Barrera-redondo, Rémy \\ Luthringer, Akira F Peters, Christophe Destombe, J. Mark Cock, Myriam \\ Valero, Denis Roze, Nicolas Salamin, et al.
}

\section{To cite this version:}

Svenja Heesch, Martha Serrano-serrano, Josué Barrera-redondo, Rémy Luthringer, Akira F Peters, et al.. Evolution of life cycles and reproductive traits: insights from the brown algae. Journal of Evolutionary Biology, 2021, 10.1111/jeb.13880 . hal-03254135

\section{HAL Id: hal-03254135 \\ https://hal.sorbonne-universite.fr/hal-03254135}

Submitted on 8 Jun 2021

HAL is a multi-disciplinary open access archive for the deposit and dissemination of scientific research documents, whether they are published or not. The documents may come from teaching and research institutions in France or abroad, or from public or private research centers.
L'archive ouverte pluridisciplinaire HAL, est destinée au dépôt et à la diffusion de documents scientifiques de niveau recherche, publiés ou non, émanant des établissements d'enseignement et de recherche français ou étrangers, des laboratoires publics ou privés. 


\section{Evolution of life cycles and reproductive traits: insights from the brown algae}

Svenja Heesch ${ }^{1,2^{*}}$, Martha Serrano-Serrano ${ }^{3^{*}}$, Josué Barrera-Redondo ${ }^{4,}$, Rémy Luthringer ${ }^{1}$, Akira F. Peters ${ }^{5}$, Christophe Destombe 6 , J. Mark Cock ${ }^{1}$, Myriam Valero 6 , Denis Roze ${ }^{6}$, Nicolas Salamin ${ }^{3}$, Susana M. Coelho ${ }^{1,4,8}$

${ }^{1}$ Sorbonne Université, UPMC Univ Paris 06, CNRS, Algal Genetics Group, Integrative Biology of Marine Models, Station Biologique de Roscoff, CS 90074, F-29688, Roscoff, France. ${ }^{2}$ Applied Ecology \& Phycology, Institute for Biosciences, University of Rostock, 18059 Rostock, Germany. ${ }^{3}$ Department of Ecology and Evolution, University of Lausanne, 1015 Lausanne, Switzerland. ${ }^{4}$ Department of Algal Development and Evolution, Max Planck Institute for Developmental Biology, Max-Planck-Ring 5, 72076, Tübingen, Germany. ${ }^{5}$ Bezhin Rosko, 29250 Santec, France. ${ }^{6}$ Evolutionary Biology and Ecology of Algae, CNRS, Sorbonne Université, UC, UACH, IRL 3614, 29688 Roscoff, France.

*Joint first authors

§correspondence: susana.coelho@tuebingen.mpg.de; josue.barrera@tuebingen.mpg.de

Running title: Evolution of life cycles in brown algae

\section{EMAIL}

SH: svenja.heesch@uni-rostock.de

MSS: marlise10@gmail.com

JBR: josue.barrera@tuebingen.mpg.de

RL: rluthringer@gmail.com

AFP: akirapeters@gmail.com

CD: destombe@sb-roscoff.fr

JMC: cock@sb-roscoff.fr

\section{ORCID}

0000-0002-4531-0921

0000-0003-3313-725X

0000-0003-4053-3840

0000-0002-2819-1238

0000-0001-5332-199X

0000-0001-5656-9659

0000-0002-2650-0383

This article has been accepted for publication and undergone full peer review but has not been through the copyediting, typesetting, pagination and proofreading process, which may lead to differences between this version and the Version of Record. Please cite this article as doi: $\underline{10.1111 / \mathrm{JEB} .13880}$

This article is protected by copyright. All rights reserved 
MV: valero@sb-roscoff.fr

DR: roze@sb-roscoff.fr

NS: Salamin@unil.ch

SMC: susana.coelho@tuebingen.mpg.de
0000-0002-9000-1423

0000-0003-3545-3504

0000-0002-3963-4954

0000-0002-9171-2550

\section{FUNDING}

This work was supported by the CNRS, Sorbonne Université and the ERC (grant agreement 638240).

\section{AUTHOR'S CONTRIBUTIONS}

SH, RL, AFP, CD, DR, SMC performed the bibliographic searches; SH, MSS, NS, JBR performed the phylogenetic analysis; SH, MSS, MV, NS, SMC, DR, JMC, CD analysed data; SMC, DR, MV, JMC, NS conceived the study; SMC coordinated the study; SH, MSS, JBR drafted and SMC wrote the final version of the manuscript, which all authors critically revised.

\section{CONFLICT OF INTEREST STATEMENT}

The authors have no conflict of interest to declare.

This article is protected by copyright. All rights reserved 
DR JOSUÉ BARRERA-REDONDO (Orcid ID : 0000-0003-4053-3840)

DR DENIS ROZE (Orcid ID : 0000-0003-3545-3504)

Article type : Research Papers

\section{Evolution of life cycles and reproductive traits: insights from the brown algae}

\section{AbStract}

A vast diversity of types of life cycles exists in nature, and several theories have been advanced to explain how this diversity has evolved and how each type of life cycle is retained over evolutionary time. Here, we exploited the diversity of life cycles and reproductive traits of the brown algae (Phaeophyceae) to test several hypotheses on the evolution of life cycles. We investigated the evolutionary dynamics of four life-history traits: life cycle, sexual system, level of gamete dimorphism and gamete parthenogenetic capacity. We assigned states to up to 77 representative species of the taxonomic diversity of the brown algal group, in a multi-gene phylogeny. We used maximum likelihood and Bayesian analyses of correlated evolution, while taking the phylogeny into account, to test for correlations between traits, and to investigate the chronological sequence of trait acquisition. Our analyses are consistent with the prediction that diploid growth evolves when sexual reproduction is preferred over asexual reproduction, possibly because it allows the complementation of deleterious mutations. We also found that haploid sex determination is ancestral in relation to diploid sex determination. However, our results could not address whether increased zygotic and diploid growth are associated with increased sexual dimorphism. Our analyses suggest that in the brown algae, isogamous species evolved from anisogamous ancestors, contrary to the commonly reported pattern where evolution proceeds from isogamy to anisogamy.

Keywords: Phaeophyceae, ploidy, sex determination, gamete size, parthenogenesis 


\section{INTRODUCTION}

The life cycle of an organism is one of its most fundamental features and influences the evolution of a variety of traits, including mode of reproduction, developmental processes, mode of dispersal, adaptation to local environment and ecological success. A wide variety of different life cycles are found within eukaryotes, and one of the great challenges of evolutionary biology is to understand how this diversity has evolved, and how each type of life cycle is retained within a lineage at evolutionary timescales (Cock et al., 2014; Mable \& Otto, 1998; Otto \& Gerstein, 2008; Valero et al., 1992).

The sexual life cycle of eukaryotes involves the fusion of two gametes to form a zygote, followed by meiosis. Such life cycles can be divided into three main types: haplontic, where only the haploid phase undergoes mitosis; diplontic, where only the diploid phase undergoes mitosis; and diplohaplontic (or haploid-diploid), where both phases undergo mitosis (Coelho et al., 2007; Otto \& Gerstein, 2008; Valero et al., 1992). In photosynthetic organisms, multicellular haploid phases are usually termed gametophytes since they produce gametes, and multicellular diploid phases are called sporophytes since they produce haploid spores. Diplohaplontic life cycles may be iso- or heteromorphic. For the latter, the dominant phase may be haploid (such as in mosses) or diploid (such as in vascular plants and kelps). Asymmetry in terms of the length and complexity of the haploid and diploid phases can be very strong (e.g., Lipinska et al., 2019) and can eventually lead to transitions towards diplontic or haplontic life cycles.

The structure of an organism's life cycle also has important consequences for the evolution of its sex determination system (Coelho et al., 2018). Haploid sex determination is common in diplohaplontic lineages such as in brown algae (Phaeophyceae), where gametophytes can either be monoicous or dioicous (Table 1). In gymnosperms and angiosperms, sex is determined in the diploid phase and the organism may be monoecious if a single individual produces female and male gametes or dioecious if male and female gametes are produced by two different individuals. Correlations between the type of sexual system and life history features such as gamete size, antheridium number, ploidy level and diversification rate are relatively well studied in angiosperms and mosses (Goldberg et al., 2017; Villarreal \& Renner, 2013) but studies of other eukaryotic groups are virtually inexistent.

One important feature of sexual life cycles in eukaryotes is the degree of similarity between male and female gametes. This 'gamete dimorphism' is a continuous trait, and a number of

This article is protected by copyright. All rights reserved 
models have been proposed to explain how anisogamous organisms could evolve from an isogamous ancestor (Hoekstra, 1980; Randerson \& Hurst, 2001). The evolution of anisogamy establishes the fundamental basis for maleness and femaleness, and leads to an asymmetry in resource allocation to the offspring, leading in many cases to sexual selection (Billiard et al., 2011). Anisogamy and oogamy have arisen repeatedly across the eukaryotes, and these systems are thought to be derived from simpler isogamous mating systems, either due to disruptive selection generated by a trade-off between the number of offspring produced and offspring survival (e.g., Bulmer \& Parker, 2002; Parker, 1978), to selection to maximize the rate of gamete encounter (e.g., Dusenbery, 2000; Togashi et al., 2012), or as a mechanism to reduce cytoplasmic conflicts (e.g., Hurst \& Hamilton, 1992; Hutson \& Law, 1993).

Differences in gamete size in anisogamous and oogamous species may influence other reproductive characteristics, such as the capacity of undergoing asexual reproduction through parthenogenesis (Billiard et al., 2011; Hoekstra, 1980). In animals and land plants, parthenogenesis has been mostly described for females only (Dawley \& Bogart, 1989), but in organisms with moderate levels of gamete dimorphism such as some brown algae, development from both male and female gametes in the absence of fertilisation is quite common, at least under laboratory conditions (e.g., Bothwell et al., 2010; Mignerot et al., 2019; Oppliger et al., 2007).

The different types of life cycles have evolved independently and repeatedly in different eukaryotic groups, and this is also the case for the types of sexual systems. Testing evolutionary hypotheses regarding the causes and consequences of life history trait diversity requires data from multiple species placed in a phylogenetic context. Such comparative studies have been hampered by a lack of accessible data regarding life cycles, sexual systems and sex determination mechanisms across the eukaryotic tree of life, and most specifically in groups outside animals and land plants. While knowledge has been recently growing in Chloroplastida, with studies extending to bryophytes and volvocine algae (Hanschen et al., 2018; Villarreal \& Renner, 2013), we still lack views on other eukaryotic groups, that should help us understand the general principles underlying the evolution of these traits.

The brown algae represent a fascinating group to study the evolution of life cycles and reproductive traits, since they exhibit a remarkable range of life cycles and sexual traits (Bell, 1997; Clayton, 1988; Figure 1). In 1997, Bell used the diversity of life cycles within the brown algae to test hypotheses on the evolution of life cycles; in particular, whether evolution generally proceeds towards an increase of the diploid phase at the expense of the haploid This article is protected by copyright. All rights reserved 
phase (Clayton, 1988), and whether a positive association between a prolonged haploid phase and the rate of inbreeding (as predicted by theories based on the effect of deleterious alleles; Otto \& Marks, 1996) is observed (using gametophyte monoicy as a proxy for inbreeding by assuming that gametophytic selfing may occur). However, his study was based on a phylogenetic tree including only 14 species, and evolutionary relationships between brown algal orders were at the time poorly resolved, making it difficult to test his assumptions.

In this study, we exploited a well-resolved phylogeny of 91 species of brown algae (Silberfeld et al., 2010; 2014) and extended it to 131 species, containing representatives from 16 of the 20 brown algae orders, which are roughly composed of $\sim 300$ genera and 2000 species (Silberfeld et al., 2014), in order to understand how life cycles and reproductive traits evolved across Phaeophyceae. We performed an extensive literature review to recover information for life cycle and reproductive traits across the brown algae. We could recover information for a maximum of 77 species, representative of most orders of brown algae (Supplemental Dataset 1). We estimated ancestral states for each of the traits, as well as the number of transitions between states and their relative timing, and assessed possible correlations between the life cycle and reproductive traits. These analyses have allowed us to describe the evolution of life cycles and reproductive traits across the brown algal phylogeny, and to test a number of long-standing hypotheses about the evolution of life cycles and reproductive traits such as: 1) the possibility that diploid growth evolved alongside a higher tendency towards sexual reproduction (Otto \& Goldstein, 1992; Otto \& Marks, 1996), 2) if increased zygotic and diploid growth are associated with increased sexual dimorphism (Bell, 1994), 3) whether haploid sex determination is ancestral in relation to diploid sex determination, 4) and if anisogamous species evolved from isogamous ancestors (Bell, 1978; Parker et al., 1972). We also tested additional hypotheses, including the possibility that gamete size influences the capacity for asexual reproduction through parthenogenesis (Luthringer et al., 2014), and we discuss the macro-evolutionary dynamics of transitions between sexual systems in the brown algae.

\section{METHODS}

\section{Molecular data}

Multiple sequence alignments were performed for 131 brown algae species, based on the nucleotide data published by Silberfeld et al. (2010; 2014), corresponding to five mitochondrial genes (atp9: mitochondrial ATP synthase subunit 9 gene, coxl and cox4: This article is protected by copyright. All rights reserved 
Cytochrome c oxidase subunit 1 and 3 genes, nadl and nad4: NADH dehydrogenase subunit 1 and 4), four chloroplast genes ( $r b c L$ : large subunit of plastid encoded ribulose-1,5biphosphate carboxylase oxygenase gene, psaA: photosystem I P700 chlorophyll a apoprotein A1 gene, psbA: photosystem II protein D1 gene, and atpB: ATP synthase subunit b gene) and one nuclear gene ( $L S U$ : large subunit of $28 \mathrm{~S}$ rRNA gene). To attribute trait states to each species we replaced some entities, depending on the availability of life-history information (i.e., kept the sequence data used to build the tree but used the data on life-history from another close relative; Table 1). Accession numbers for the sequences of the species that were not included in Silberfeld $(2010 ; 2014)$ are in Table S1. No information was available about the life histories of the closest relatives of the Phaeophyceae, e.g., Phaeothamniophyceae, so we used Schizocladia and Vaucheria as outgroups, both heterokont genera from the classes Schizocladiophyceae and Xanthophyceae from which Vaucheria had available life cycle and reproductive trait information. The final species list used for the trait analysis, for which we had life cycle and reproductive trait information, was comprised of 77 species, including the outgroup.

\section{Phylogenetic reconstruction}

We used the sequence data from the 131 brown algae species to infer a phylogenetic tree (Figure 1). All sequences were aligned using MAFFT (Katoh et al., 2009), and the best substitution models were estimated as $G T R+G$ for three different gene partitions, corresponding to the nuclear, plastid and mitochondrial genes using the phymltest function in the ape R package (Paradis et al., 2004). The concatenated alignment (Supplemental Dataset 2; TreeBASE submission ID S28254) was used for Bayesian Inference with Beast v1.8.2 (Drummond et al., 2012). Each partition was unlinked for the substitution model. We used birth-death with incomplete sampling as tree prior, and four calibration nodes as described in Silberfeld et al. (2010) (see nodes 1 to 4, Figure 2). We used log-normal priors for two of the calibrations: Padina-like clade 1, lognormal distribution (mean $5 \mathrm{Ma}$, sd 1, and lower boundary at 99.6 Ma); Nereocystis-Pelagophycus clade 2: lognormal distribution (mean 20 Ma, sd 1, and lower boundary at $13 \mathrm{Ma}$ ), normal priors for the root (Phaeophyceae root age 4: normal distribution $(\mathrm{u}=155, \mathrm{sd}=30 \mathrm{Ma})$, and a normal distribution for the Sargassaceae node $3(\mathrm{u}=60, \mathrm{sd}=15$, with lower boundary $13 \mathrm{Ma})$. We also included a prior to separate Phaeophyceae as a monophyletic clade. Finally, the MCMC was set to 50 million generations with a sampling every 1,000 generations and a subsequent burn-in of $16 \%$ of the sampled trees. The posterior distribution was summarized using Treeannotator v1.7.0 (Drummond et This article is protected by copyright. All rights reserved 
al., 2012) to obtain a Common Ancestor Tree (Heled \& Bouckaert, 2013; Supplemental Dataset 2; TreeBASE submission ID S28254). For the macroevolutionary analyses (see below), a set of 100 trees were sampled from the posterior distribution.

\section{Life history traits}

We estimated the ancestral state of each of the four main sexual traits: type of life cycle (haploid > diploid; haploid = diploid; haploid < diploid; diplont), type of sexual system (monoicous; dioicous; monoecious; dioecious), level of gamete dimorphism (isogamous; anisogamous; oogamous), and parthenogenetic capacity (no parthenogenesis; parthenogenesis in female gametes only; parthenogenesis in both male and female gametes) The traits were coded as discrete multi-state characters (Table 2). Definitions of the life cycle and sexual terms used in this study are provided in Table 1. We separated the respective traits into seven additional characters. For example, we transferred 'gamete size' (iso-, aniso-, oogamous) into a continuous male gamete size trait. We furthermore recoded multi-state traits into binary data for the correlation tests (see below), such as the 'gamete dimorphism', which was recorded by separating the absence $(0=$ oogamy $)$ from presence $(1=$ iso- or anisogamy $)$ of female flagellated gametes. We categorized an additional sexual system trait as 'sexes occurring on the same thallus' $(0=$ monoicous or monoecious $)$ or 'separate thalli' $(1=$ dioicous or dioecious). The life cycle was simplified to the occurrence of a 'dominant haploid phase' ( $0=$ haploid $\geq$ diploid $)$ versus dominance of the diploid phase $(1=$ haploid $<$ diploid or diplontic), with dominance broadly meaning size of the adult individual. Finally, the occurrence of parthenogenesis was separated into two additional traits, absence (0) or presence (1) of male parthenogenesis, and absence of parthenogenesis (0) versus parthenogenesis occurring in at least one of the sexes (1), most commonly the female.

We coded as "isogamous" algae with physiological and behavioural anisogamy but that have been described as having no size difference between male and female gametes. Note that all brown algae exhibit an asymmetry between male and female, at least at the level of their behaviour, and potentially all the algae scored as isogamous have in fact subtle size differences, but the literature is not detailed enough in this respect. For example, most representatives of the order Ectocarpales have been reported to be 'isogamous' (based on observations under the light microscope, but without detailed measurements of gamete size), but some members (Ectocarpus sp., Colpomenia peregrina Sauvageau) have anisogamous male and female gametes (Lipinska et al., 2015). Anisogamy is also present in Asterocladon 
interjectum Uwai, Nagasato, Motomura et Kogame, which belongs to the last order branching off before the Ectocarpales.

The Laminariales, which is sister group to the clade formed by Ectocarpales and Asterocladales, is almost completely oogamous, with the exception of the genus Saccharina, which has been shown to have eggs with rudimentary flagella (Motomura \& Sakai, 1988) being therefore considered strongly anisogamous.

\section{Ancestral state reconstructions and correlation analysis}

A likelihood-based method was used to reconstruct the ancestral state of each of the four lifehistory traits. We fitted three different models of trait evolution using the function fitDiscrete from the R package Geiger (Harmon et al., 2008). These models differed in the number of transition rates as follows: equal rates (ER, a single transition rates between all states), symmetric (SYM, forward and reverse transitions are the same), and all-rates-different (ARD, each rate is a unique parameter). The corrected Akaike Information Criterion (AICc) was used to compare the alternative models. Each model was estimated on each 100 phylogenetic trees sampled from the posterior distribution to account for uncertainty in tree topology and divergence times. We pruned species from the trees that lacked phenotypic data for the reconstruction of each life-history trait. State probabilities at the root and transition rates were summarized with the mean and standard deviation values of all iterations, to incorporate phylogenetic uncertainty.

We inferred the number of transitions between states, and their minimum timing, using stochastic character mapping (Huelsenbeck et al., 2003). One hundred stochastic mappings were performed on the posterior sample of trees, and on each we divided branch lengths into time bins of $1 \mathrm{Myr}$ and recorded the number of transitions from and to each state, in each bin (as described in Serrano-Serrano et al., 2017). We reported the mean and standard deviation, and the time bin at which $60 \%$ of the stochastic mappings had at least one transition event as the onset time for each type of transition.

We assessed correlation between binary life history traits using the reversible-jump MCMC algorithm implemented in BayesTraits V3 (Pagel et al., 2004). This approach compared two models, a null model assuming that the traits had evolved independently, and an alternative model assuming that their evolution had been correlated. Each model was run for 10 million generations using the values found in the ancestral state reconstructions for the root state. The two models were compared through their log marginal likelihood by estimating the log Bayes

This article is protected by copyright. All rights reserved 
factor. This approach was used to test the correlation between female parthenogenesis and the occurrence of sexes on the same versus separate thalli. Tests showing a significant support for the correlated model were presented as networks of evolutionary transitions using the $\mathrm{R}$ package qgraph (Epskamp et al., 2012).

We also used the threshold model of threshBayes in the R package phytools (Revell, 2014), to test for the correlation between a continuous and a discrete variable. The threshold model assumes that the states of discrete phenotype are governed by an unobserved continuous character called liability. These liabilities are assumed to evolve according to a Brownian motion model (Felsenstein, 2012) and translate into discrete characters once they have passed certain thresholds. We used this model to test the correlation between male gamete size and two discrete traits, male parthenogenesis and sexes on the same or on separate thalli.

For correlation analyses that were significant, we fitted an Ornstein-Uhlenbeck model of evolution by using OUwie from the R package Ouwie (Beaulieu et al., 2012) to further test whether the continuous trait had two discrete selective regimes, determined by the discrete binary trait. We compared the alternative models using the corrected Akaike Information Criterion (AICc)-selected model.

\section{RESULTS}

\section{Ancestral state estimations and transitions between states}

Our ancestral state reconstructions inferred equal rates of transition (ER model) between states for all traits, except for the trait 'sexual system' where rates were different between states but symmetrical (SYM model gain or loss of a trait). These patterns indicate an overall complex evolutionary history for all sexual traits, involving multiple gains and losses (Figure 2, Table S2).

Life cycle. On the basis of ancestral state reconstructions, the ancestor of all brown algae had a diplohaplontic life cycle, with either isomorphic generations or with a larger and morphologically more complex diploid than haploid generation (Figure 2A, Table S2). Transitions between life cycles occurred most frequently from diploid-dominant to equally dominant generations, involving a decrease in complexity in terms of the sporophyte morphology (number of different cell types, number of tissues and organs) and a concomitant increase in the complexity of the gametophyte (Figure 2A). A change of dominance from a diploid-dominant to a haploid-dominant life cycle occurred for the first time in the last 
common ancestor of the Scytosiphonaceae family, at least $57.5( \pm 5.05)$ My ago, with another independent transition in Cutleria multifida (Turner) Greville (Figure 2A-B). Transitions from a diploid-dominant to a fully diploid life cycle occurred three times, about $74.5( \pm 21.41)$ My ago in the ancestor of the diploid order Fucales, in the ancestor of Ascoseirales and in the ancestor of Tilopteris mertensii (Turner) Kützing. Note however that Tilopteris mertensii is a rather particular case within Tilopteridales (Kuhlenkamp \& Müller, 1985), and emergence of monoecy in this species should be interpreted with caution.

Overall, our analysis indicated that the dominance relationship between life cycle generations has been a labile trait in the brown algae, with the diplontic life cycle being the only irreversible state.

Sexual system. The last common ancestor of all brown algae is predicted to have exhibited haploid sex determination and was most likely dioicous (Figure 2A-D, Table S2), but several independent transitions towards monoicy have occurred (Figure 2C-D). The transition from haploid to diploid sex determination, which involved a transition from dioicy to monoecy, occurred independently in the last common ancestor of the order Fucales about 74.5 My ago, in Ascoseirales and in Tilopteris mertensii. The three transitions were simultaneous with the transition from a diplohaplontic to a diplontic life cycle (Figure 2B, 2D). Dioecy appears to have emerged more recently, around 17.5 Mya, in most families of the order Fucales, with the exception of Sargassaceae and Notheiaceae, which remained monoecious. Further transitions back to monoecy occurred in several genera of the Fucaceae (Xiphophora, Pelvetia and Seirococcus) (Table S2, Figure 2C-D).

Overall, our analysis suggests that the transition to diploid sex determination is irreversible and concomitant with a change in the type of life cycle (from diplohaplontic to diplontic life cycle). In contrast, transitions between separate sexes and combined sexes occurred frequently, either in the haploid or in the diploid phase.

Sexual dimorphism. Regarding gamete size dimorphism, our analysis suggests that oogamy is most likely the ancestral state in the brown algae (Table S2, Figure 2E-F). The oldest transition took place around $114 \mathrm{My}$ ago, from oogamy to isogamy in the lineage leading to the basal brown algal orders Sphacelariales and Syringodermatales. Another independent transition from oogamy to isogamy took place in the Ascoseirales. Isogamy also emerged in the Ectocarpales, with several independent transitions to anisogamy. Nonetheless, transitions from oogamy to anisogamy were the most frequent transition throughout the phylogeny.

This article is protected by copyright. All rights reserved 
Taken together, the results indicate that gamete size dimorphism level is a remarkably labile trait in the brown algae.

Parthenogenesis. The gametes of the ancestral brown algae are predicted to have been unable to perform asexual reproduction through parthenogenesis (Figure 2G-H). The initial transition from absence of parthenogenesis to female gamete parthenogenesis could not be accurately traced in time along the early diverging branch separating the subclass Fucophycideae from the earlier branching Dictyophycidae. The length of this branch renders identification of the transition during 1 My time bins impossible, as most events fall in different time periods and agreement between reconstructions is very low. The oldest traceable transition that could be timed $(85.5 \mathrm{My})$ and also the one with the highest frequency, was from female-only parthenogenesis to parthenogenesis of both female and male gametes in the order Ectocarpales. A subsequent loss of parthenogenesis can be traced to the last common ancestor of the order Fucales. Note that parthenogenesis is the trait with the lowest sampling, as there are very limited data about this trait in the literature.

\section{Generation dominance and sexual system}

Transitions in life cycle phase dominance probabilities were higher in monoicous compared to dioecious species, whatever the direction (q21 and q12 > q43 and q34; Figure 3, Figure S1). In other words, monoicous species exhibit higher turnover rates in terms of generation dominance. Moreover, transitions from monoicous to dioicous states were slightly more frequently observed than transitions from dioicous to monoicous, regardless of life cycle phase dominance (Bayes Factor of 3.51 in favour of the dependent model with q24 q13 > q42 q31, Figure 3).

\section{Generation dominance and sexual dimorphism}

We tested if diploid dominance is correlated with an increase in sexual dimorphism. The test of the dependent versus independent model showed that the difference in likelihood was not significant $(\log \mathrm{BF}=-0.1080$, Table S3), suggesting that the evolution of these traits is not correlated. Therefore, our data do not support the hypothesis that diploid growth is associated with increased sexual dimorphism. It should be noted, however, that the low number of transitions between both traits may limit the statistical power of this correlation.

This article is protected by copyright. All rights reserved 


\section{Gamete biology and sexual systems}

Based on the idea that gamete dimorphism evolved to maximize the chances of gamete encounters, one may hypothesise that separate sexes (dioecy and dioicy) would be associated with small and abundant male gametes, as a mechanism to ensure that the gametes find a partner of the opposite sex when gametes are released into seawater. However, we found no evidence for an association between male gamete size and sexual system (sexes on same versus different individuals) (Figure S2, Table S3, r=0.0909).

When gametes are produced by two separate individuals, it may be more difficult for a gamete to find a gamete of the opposite sex than if the same individual produces gametes of both sexes. Accordingly, we hypothesised that parthenogenesis would be favoured in species with separate sexes, as opposed to the situation where male and female gametes are produced by the same individual (note that auto-incompatibility has not been described in the brown algae, with the exception of one study (Gibson, 1994)). However, we found no evidence that parthenogenesis was more prevalent in species with separate sexes (Table S3).

Finally, we investigated the relationship between the size of male gametes and their parthenogenetic capacity, under the hypothesis that there is a minimum threshold size for male gametes, below which parthenogenesis is not possible. The phylogenetic threshold model indicated that there is a positive correlation between male gamete size and parthenogenetic capacity (Table S3, r=0.4242), however the highest posterior density (HPD) interval of this correlation includes zero. We therefore complemented this analysis using an Ornstein Uhlenbeck (OU) model. The estimated optimal size for non-parthenogenetic male gametes is significantly lower than that of parthenogenetic male gametes (5.49 um vs 9.30 um; Figure S1, Figure 4), further supporting a correlation between male gamete size and male parthenogenesis.

\section{DISCUSSION}

Several hypotheses have been proposed to explain the evolution of life cycles in eukaryotic lineages (Otto \& Gerstein, 2008; Otto \& Marks, 1996; Valero et al., 1992). We used 131 species that are representative of the major groups within Phaeophyceae (Silberfeld et al., 2014) to calibrate the divergence time in our phylogeny, and used 77 of those species to test some of these hypotheses. The taxonomic sampling in this study greatly exceeds those of previous attempts at understanding the evolution of life cycles in brown algae, with only 14 species (Bell, 1997), as well as recent publications where divergence times were calculated This article is protected by copyright. All rights reserved 
using 44 and 91 species (Silberfeld et al., 2014; Kawai et al., 2015). We found differences in the phylogenetic relationships among brown algae orders compared to Kawai et al. (2015), such as the placement of Scytothamnales and Syringodermatales, or the relative placement of Tilopteridales and Ralfsiales alongside Fucales. These discrepancies could arise from differences in the molecular markers used for the phylogenetic reconstruction, as Kawai et al. (2015) used six chloroplast genes and one mitochondrial gene, while we used four chloroplast genes, five mitochondrial genes and one nuclear gene. Future phylogenomic studies will likely shed light on some of these discrepancies. Although Kawai et al. (2015) were able to collect molecular data from Stschapoviales and Onslowiales, which could not be integrated to our dataset, we were able to obtain molecular data from Asterocladales and Nemodermatales, as well as a higher taxonomic sampling from most of the brown algae orders, allowing us to better pinpoint the transition events in trait evolution. We found a limited number of state transitions for each trait throughout the phylogeny, which limited the statistical power of our correlation analyses, and thus the extent of our conclusions. Nonetheless, we were able to find some instances of correlated evolution between traits that helped us take a step forward in understanding some aspects of the evolution of life cycles.

We found several coincidental trait transitions leading to the common ancestor of Fucales 74.5 My ago, after its split with Nemodermatales. During this time, sea levels rose $100 \mathrm{~m}$ above present-day levels (Surlyk \& Sørensen, 2010). The extant species of Fucales inhabit the intertidal and subtidal zones (Schiel \& Foster, 2006), so the rising of sea levels possibly opened new ecological niches for these taxa, allowing the emergence of evolutionary novelty. We found another important transition at least $\sim 57.5 \mathrm{My}$ ago from a diploid-dominant to a haploid-dominant life cycle in the last common ancestor of Scytosiphonaceae. This event coincides with the Paleocene-Eocene Thermal Maximum, a major geological event where temperature increased and large amounts of carbon were introduced to the oceans through volcanic activity, leading to many changes in marine ecosystems (Ma et al., 2014).

Is diploid growth indirectly associated to sexual reproduction as a way to complement deleterious mutations?

Our results indicate that the ancestral brown algae likely had a diplohaplontic life cycle with similar diploid and haploid dominance (i.e., similar size and complexity of the gametophyte and sporophyte generations). Over evolutionary time, the diploid phase became dominant in some clades, whereas other clades evolved towards greater haploid dominance. Several theories have been proposed to explain evolution towards either a dominant haploid or a This article is protected by copyright. All rights reserved 
dominant diploid phase in the life cycle (e.g., Otto \& Gerstein, 2008). Hypotheses based on the effect of deleterious alleles have proposed that being diploid generally increases mean fitness due to the masking of deleterious alleles (due to complementation of these alleles by non-mutant alleles), while developing as a haploid allows more efficient purging of deleterious alleles because they are exposed to selection (Otto \& Goldstein, 1992; Rescan et al., 2016; Scott \& Rescan, 2017). The balance between these two forces determines whether evolution proceeds towards an increase of the haploid or the diploid phase, and depends critically on the importance of sexual exchanges within populations. Indeed, under higher rates of inbreeding or asexual reproduction, the benefit of purging deleterious alleles remains associated with alleles increasing the haploid phase, therefore haploidy is favoured. In contrast, outcrossing and/or more frequent sex tend to favour diploidy (Otto \& Marks, 1996). In accordance with this hypothesis, our results show that the last common ancestor of Fucales transitioned to a loss of parthenogenesis alongside a fully diplontic life cycle, while the haplontic family Scytosiphonaceae conserved both female and male parthenogenesis. Nonetheless, a direct correlation between deleterious mutations and phase dominance remains to be tested. To test this hypothesis, future studies should look for correlations between the dominance of the haploid or diploid phase with changes in the accumulation of nonsynonymous mutations in the nuclear genome, as diploid-dominant taxa are expected to maintain a higher fitness than haploid-dominant taxa after the accumulation of substitution events (Scott \& Rescan, 2016).

Very few estimates of inbreeding coefficients or rates of asexual reproduction are available for brown algae, with most of them being done in Laminariales and Fucales (Bringloe et al., 2020). However, this idea was tested by Bell (1997) by looking at the correlation between the sexual system of a species (monoicous or dioicous) and the relative dominance of the haploid and diploid phases of the life cycle, assuming that monoicous species will tend to be more inbred due to selfing. At the time, Bell concluded that monoicous species did not tend to have more dominant haploid phases (Bell, 1997). In contrast to Bell's analysis, which was based on a small number of brown algal species, our results do appear to support Otto and Marks' (1996) ideas, at least to some extent, because transitions towards dominance of the haploid phase were found to be more frequent when the sexual system was monoicous, consistent with the idea that monoicy is correlated with haploid growth. Generating novel data on estimates of inbreeding coefficients within natural populations of monoicous species would be extremely valuable to shed further light into these phenomena.

This article is protected by copyright. All rights reserved 
Somatic mutations have been proposed as another possible source of selection for diploidy, as these mutations should have a lower impact on the fitness of diploid organisms (e.g., Otto \& Gerstein, 2008). This idea is consistent with the general observation that larger organisms tend to be diploid rather than haploid, as in the case of vascular against nonvascular plants (Schoen \& Schultz, 2019). Indeed, this pattern also holds true for the brown algae, since all the largest brown algae (e.g., Laminariales, Fucales) have a dominant diploid phase. Empirical estimates of somatic mutations in haplontic and diplontic taxa and their effects on fitness could help test this hypothesis (e.g., Yu et al., 2020).

\section{Is diploid growth associated with increased gamete dimorphism?}

The theory for the evolution of gamete dimorphism based on the trade-off between gamete number and offspring fitness predicts that dimorphism may evolve when zygote size has a strong effect on fitness (i.e., when offspring fitness increases more than linearly in relation to zygote size). Accordingly, one may predict that if a larger zygote size is needed for larger diploid development, increased diploid growth would favour higher levels of gamete dimorphism (Parker et al., 1972). Bell (1994) proposed an alternative theory that also predicts a correlation between diploid growth and gamete dimorphism, in which the direction of causality is reversed (i.e., sexual selection caused by gamete dimorphism favouring diplontic cycles in order to increase genetic differences between gametes produced by the same organism). Our results show that diplontic brown algal species are mostly oogamous, suggesting a link between strong sexual dimorphism and diploidy. However, those associations may not reflect a general tendency, because they are mainly based on the Fucales and Tilopteris mertensii, whereas Ascoseirales transitioned towards isogamy alongside a diplontic life cycle. Therefore, more analyses are needed to explore the idea that diploid growth is associated with increased sexual dimorphism.

\section{Evolution of sexual systems in the brown algae}

Our results indicate that the ancestral sexual system of brown algae corresponds to haploid sex determination and dioicy, with several transitions towards monoicy having occurred independently over evolutionary time. Transition towards a diplontic life cycle in the Fucales, Ascoseirales and Tilopteris mertensii appears to have involved a monoecious/hermaphrodite intermediate state, with subsequent independent re-emergence of dioecy in some lineages of Fucales. It is interesting to note that transitions from separate sexes to co-sexuality are relatively frequent in haploid sexual systems, which contrasts with what is the most

This article is protected by copyright. All rights reserved 
commonly accepted direction of evolution in clades with diploid sex determination (i.e., monoecy to dioecy). Note, however, that although dioecy was considered to be an evolutionary dead end in angiosperms (Vamosi \& Otto, 2002), more recent phylogenetic analysis are challenging this conclusion, and the idea that reversals to monoecy in angiosperms may be more frequent than thought before is increasingly becoming accepted (Käfer et al., 2017; Pannell, 2017).

In diploid sexual systems, two main selective effects have been proposed to explain transitions from co-sexuality to dioecy: inbreeding depression (selfing is less likely to occur when male and female gametes are produced by separate individuals) and the effect of tradeoffs between male and female fitness (Charlesworth \& Charlesworth, 1978; Charnov, 1982). In haploid sexual systems, the opposite transition (from separate sexes towards co-sexuality) could also be caused in principle by a change in the shape of the trade-off between male and female reproductive success (leading to a higher fitness of gametophytes producing both types of gametes) or by selection for inbreeding (selfing), either through the automatic transmission advantage associated with selfing (Fisher, 1941), or for reproductive assurance when population density is low. Note, however, that parthenogenesis occurs in all monoicous species, and this process may represent an alternative way of dealing with mate limitation and reproductive assurance. Assuming that selfing occurs following transitions to monoicy, such transitions should occur more easily when inbreeding depression is low. More transitions to monoicy in taxa with a prolonged haploid phase (if at least a proportion of the deleterious alleles affecting the fitness of diploids will be purged during the haploid phase of the life cycle) would therefore be expected, but this is not what we observe in our results $(\mathrm{q} 31<\mathrm{q} 42$, Fig. 3). Examining the proximate mechanisms involved in the transitions between separate sexes and co-sexuality in both haploid and diploid systems and more natural population data, for example in populations with different densities, would be valuable to shed light on the mechanisms and evolutionary forces driving the shifts among sexual systems in the brown algae.

\section{Anisogamy is ancestral in the brown algae}

In agreement with the tendencies observed by Silberfeld et al. (2010), our analysis points towards an oogamous ancestor of brown algae, with several independent transitions towards anisogamous and isogamous clades. This stands in contrast to theoretical scenarios representing the evolution of gamete dimorphism from an isogamous ancestor (e.g., Lehtonen \& Koko, 2011; Parker et al., 1972; Randerson \& Hurst, 2001), in which isogamy is ancestral This article is protected by copyright. All rights reserved 
and anisogamy represents an intermediate step during the process of increased gametic differentiation. The transition from oogamy to isogamy has also been reported in diatoms, where possible explanations included reproductive adaptations such as physical proximity, mucilage envelopes or copulation tubes that facilitate the success rates in the pairing of gametes, changing the selective pressures that favour oogamy (Edlund \& Stoermer, 1997). Theories based on disruptive selection caused by a trade-off between the number of gametes produced and zygote size (e.g., Bulmer \& Parker, 2002; Parker et al., 1972) have shown that the shape of the relation between zygote size and fitness is critical for the evolution of gamete dimorphism. It would be interesting to explore whether a change in the relation between zygote size and fitness (for example, due to a decrease in size of the diploid organism) may favour transitions from oogamy to anisogamy or isogamy. This type of evolutionary mechanism may generate a positive correlation between the degree of gamete dimorphism and the relative importance of the diploid phase, leading to an inversion of the causal relationship in Bell's $(1994 ; 1997)$ hypothesis mentioned above, i.e., decrease in the size of the diploid organism would drive a decrease in gamete dimorphism.

The evolution of anisogamy requires some level of gametic competition and limitation (Lehtonen \& Kokko, 2011). Therefore, it is likely that in specific conditions the system may return to isogamy or near isogamy, for instance, if there is a low level of gamete competition or if there is no gamete limitation.

\section{Evolution of gamete size and parthenogenetic capacity}

Our results point towards a possible correlation between the capacity of brown algae to perform male parthenogenesis and male gamete size. There are marked differences between the relative parthenogenetic capacities of male and female gametes in isogamous, anisogamous and oogamous brown algal species (Luthringer et al., 2014). It has been suggested that increased gamete size leads to increased parthenogenetic capacity, up to a point, but that in oogamous species, the large female gamete loses its flagella becoming specialised for zygote production, often losing its capacity to initiate parthenogenetic development (Luthringer et al., 2014).

Our results indicate that the gametes of the common ancestor of brown algae were most likely unable to perform asexual reproduction through parthenogenesis, suggesting that the emergence of gamete parthenogenetic capacity was derived, perhaps as an adaptive trait in situations where mates are limited, such as in marginal populations (Bierzychudek, 1985;

This article is protected by copyright. All rights reserved 
Oppliger et al., 2014). Data from field populations of a range of species would be needed to further understand whether parthenogenesis is adaptive. It is noteworthy that parthenogenetic capacity is assessed under laboratory conditions, and that the contribution of parthenogenesis to recruitment in natural populations would be worth exploring further (Oppliger et al., 2007; 2014). A recent study in field populations of Ectocarpus showed no evidence that parthenogenesis plays a significant role under field conditions (Couceiro et al., 2015). In contrast, studies in field populations of another brown algal species, Scytosiphon lomentaria (Lyngbye) J. Agardh suggested that parthenogenesis is prevalent in field populations (Hoshino et al., 2018). Interestingly, female-only parthenogenetic populations have larger gamete sizes relative to 'sexual' populations of the same species, consistent with a link between gamete size and parthenogenetic capacity, and opening the possibility that parthenogenesis may be an adaptive trait.

Overall, our results reveal that the emergence and dominance of certain life history traits within the brown algae are associated throughout the evolutionary history of this lineage. These correlations uncovered clues about the evolutionary processes governing the origin of fundamental biological features in eukaryotes, such as the dominance of the haploid or diploid phases throughout the life cycle, the emergence and loss of sexual dimorphism and the evolvability of parthenogenesis. Moreover, our reconstruction of ancestral states highlights the unusual evolutionary history of brown algae, showing that oogamous lineages can revert to an isogamous state, that parthenogenesis can emerge in male gametes, and that transitions between monoicous and dioicous states can be very dynamic, with dioicous transitions being more frequent. Despite the considerable rate of trait transitions within the phylogeny, we found that diplontic life cycles and diploid sex determination are both stable and seemingly irreversible, suggesting they are highly advantageous. The advantage of complementing deleterious mutations in diplontic taxa (Otto \& Goldstein, 1992; Rescan et al., 2016; Scott \& Rescan, 2017) and its concomitance with diploid sex determination may be responsible for the irreversibility of these traits, and would likely explain why they are the prevailing biological traits in the plant and animal lineages.

\section{DAta AVAILABILITY Statement}

The nucleotide sequences used for the phylogenetic reconstruction are available in GenBank (https://www.ncbi.nlm.nih.gov/genbank/) with the accession numbers published by Silberfeld et al. $(2010 ; 2014)$ and in Table S1. The concatenated multiple sequence alignment and the

This article is protected by copyright. All rights reserved 
Common Ancestor Tree obtained from BEAST are available in TreeBASE (submission ID S28254).

\section{REFERENCES}

Beaulieu, J.M., Jhwueng, D.C., Boettiger, C., \& O’Meara, B.C. (2012). Modeling stabilizing selection: expanding the Ornstein-Uhlenbeck model of adaptive evolution. Evolution, 66(8), 2369-2383. https://doi.org/10.1111/j.1558-5646.2012.01619.x

Bell, G. (1978). The evolution of anisogamy. Journal of Theoretical Biology, 73(2), 247-270. https://doi.org/10.1016/0022-5193(78)90189-3

Bell, G. (1994). The comparative biology of the alternation of generations. Lectures on mathematics in the life sciences, 25, 1-26.

Bell, G. (1997). The evolution of the life cycle of brown seaweeds. Biological Journal of the Linnean Society, 60(1), 21-38. https://doi.org/10.1111/j.1095-8312.1997.tb01481.x

Bierzychudek, P. (1985). Patterns in plant parthenogenesis. Experientia, 41(10), 1255-1264. https://doi.org/10.1007/BF01952068

Billiard, S., López-Villavicencio, M., Devier, B., Hood, M.E., Fairhead, C., \& Giraud, T. (2011). Having sex, yes, but with whom? Inferences from fungi on the evolution of anisogamy and mating types. Biological reviews, 86(2), 421-442. https://doi.org/10.1111/j.1469-185X.2010.00153.X

Bothwell, J.H., Marie, D., Peters, A.F., Cock, J.M., \& Coelho, S.M. (2010). Role of endoreduplication and apomeiosis during parthenogenetic reproduction in the model brown alga Ectocarpus. New Phytologist, 188(1), 111-121. https://doi.org/10.1111/j.1469-8137.2010.03357.x

Bringloe, T.T., Starko, S., Wade, R.M., Vieira, C., Kawai, H., De Clerck, O., Cock, J.M., Coelho, S.M., Destombe, C., Valero, M., Neiva, J., Pearson, G.A., Faugeron, S., Serrão, E.A., \& Verbruggen, H. (2020). Phylogeny and evolution of the brown algae. Critical Reviews in Plant Sciences, 39(4), 281-321. https://doi.org/10.1080/07352689.2020.1787679

Bulmer, M.G., \& Parker, G.A. (2002). The evolution of anisogamy: a game-theoretic approach. Proceedings of the Royal Society of London. Series B: Biological Sciences, 269(1507), 2381-2388. https://doi.org/10.1098/rspb.2002.2161

This article is protected by copyright. All rights reserved 
Charlesworth, B., \& Charlesworth, D. (1978). A model for the evolution of dioecy and gynodioecy. The American Naturalist, 112(988), 975-997. https://doi.org/10.1086/283342

Charnov, E.L. (1982). The Theory of Sex Allocation. Princeton University Press.

Clayton, M.N. (1988). Evolution and life histories of brown algae. Botanica Marina, 31(5), 379-388. https://doi.org/10.1515/botm.1988.31.5.379

Cock, J.M., Godfroy, O., Macaisne, N., Peters, A.F., \& Coelho, S.M. (2014). Evolution and regulation of complex life cycles: a brown algal perspective. Current Opinion in Plant Biology, 17, 1-6. https://doi.org/10.1016/j.pbi.2013.09.004

Coelho, S.M., Gueno, J., Lipinska, A.P., Cock, J.M., \& Umen, J.G. (2018). UV chromosomes and haploid sexual systems. Trends in Plant Science, 23(9), 794-807. https://doi.org/10.1016/j.tplants.2018.06.005

Coelho, S.M., Peters, A.F., Charrier, B., Roze, D., Destombe, C., Valero, M., \& Cock, J.M. (2007). Complex life cycles of multicellular eukaryotes: new approaches based on the use of model organisms. Gene, $\mathbf{4 0 6}(1-2), \quad$ 152-170. https://doi.org/10.1016/j.gene.2007.07.025

Couceiro, L., Le Gac, M., Hunsperger, H.M., Mauger, S., Destombe, C., Cock, J.M., Ahmed, S., Coelho, S.M., Valero, M., \& Peters, A.F. (2015). Evolution and maintenance of haploid-diploid life cycles in natural populations: The case of the marine brown alga Ectocarpus. Evolution, 69(7), 1808-1822. https://doi.org/10.1111/evo.12702

Dawley, R., \& Bogart, J. (1989). The evolution and ecology of unisexual vertebrates. Albany, NY: The New York State Museum.

Drummond, A.J., Suchard, M.A., Xie, D., \& Rambaut, A. (2012). Bayesian phylogenetics with BEAUti and the BEAST 1.7. Molecular Biology and Evolution, 29(8), 19691973. https://doi.org/10.1093/molbev/mss075

Dusenbery, D.B. (2000). Selection for high gamete encounter rates explains the success of male and female mating types. Journal of Theoretical Biology, 202(1), 1-10. https://doi.org/10.1006/jtbi.1999.1017

Edlund, M.B., \& Stoermer, E.F. (1997). Ecological, evolutionary, and systematic significance of diatom life histories. Journal of Phycology, 33(6), 897-918. https://doi.org/10.1111/j.0022-3646.1997.00897.x

This article is protected by copyright. All rights reserved 
Epskamp, S., Cramer, A. O., Waldorp, L. J., Schmittmann, V. D., \& Borsboom, D. (2012). qgraph: Network visualizations of relationships in psychometric data. Journal of Statistical Software, 48(4), 1-18. http://hdl.handle.net/10.18637/jss.v048.i04

Felsenstein, J. (2012). A comparative method for both discrete and continuous characters using the threshold model. The American Naturalist, 179(2), 145-156. https://doi.org/10.1086/663681

Fisher, R.A. (1941). Average excess and average effect of a gene substitution. Annals of Eugenics, 11(1), 53-63. https://doi.org/10.1111/j.1469-1809.1941.tb02272.x

Gibson, M. (1994). Reproduction in Cladostephus spongiosus in southern Australia (Sphacelariales, Phaeophyceae). Phycologia, 33(5), 378-383. https://doi.org/10.2216/i0031-8884-33-5-378.1

Goldberg, E.E., Otto, S.P., Vamosi, J.C., Mayrose, I., Sabath, N., Ming, R., \& Ashman, T.L. (2017). Macroevolutionary synthesis of flowering plant sexual systems. Evolution, 71(4), 898-912. https://doi.org/10.1111/evo.13181

Hanschen, E.R., Herron, M.D., Wiens, J.J., Nozaki, H., \& Michod, R.E. (2018). Repeated evolution and reversibility of self - fertilization in the volvocine green algae. Evolution, 72(2), 386-398. https://doi.org/10.1111/evo.13394

Harmon, L.J., Weir, J.T., Brock, C.D., Glor, R.E., \& Challenger, W. (2008). GEIGER: investigating evolutionary radiations. Bioinformatics, 24(1), 129-131. https://doi.org/10.1093/bioinformatics/btm538

Heled, J., \& Bouckaert, R.R. (2013). Looking for trees in the forest: summary tree from posterior samples. BMC Evolutionary Biology, 13(1), 1-11. https://doi.org/10.1186/1471-2148-13-221

Hoekstra, R.F. (1980). Why do organisms produce gametes of only two different sizes? Some theoretical aspects of the evolution of anisogamy. Journal of Theoretical Biology, 87(4), 785-793. https://doi.org/10.1016/0022-5193(80)90117-4

Hoshino, M., Okino, T., \& Kogame, K. (2019). Parthenogenetic female populations in the brown alga Scytosiphon lomentaria (Scytosiphonaceae, Ectocarpales): decay of a sexual trait and acquisition of asexual traits. Journal of Phycology, 55(1), 204-213. https://doi.org/10.1111/jpy.12812

This article is protected by copyright. All rights reserved 
Huelsenbeck, J.P., Nielsen, R., \& Bollback, J.P. (2003). Stochastic mapping of morphological

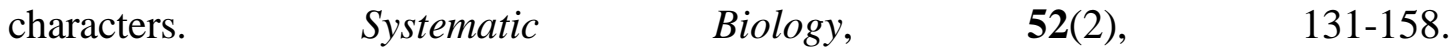
https://doi.org/10.1080/10635150390192780

Hurst, L.D., \& Hamilton, W.D. (1992). Cytoplasmic fusion and the nature of sexes. Proceedings of the Royal Society of London. Series B: Biological Sciences, 247(1320), 189-194. https://doi.org/10.1098/rspb.1992.0027

Hutson, V., \& Law, R. (1993). Four steps to two sexes. Proceedings of the Royal Society of London. Series B: Biological Sciences, 253(1336), 43-51. https://doi.org/10.1098/rspb.1993.0080

Käfer, J., Marais, G.A., \& Pannell, J.R. (2017). On the rarity of dioecy in flowering plants. Molecular Ecology, 26(5), 1225-1241. https://doi.org/10.1111/mec.14020

Katoh, K., Asimenos, G., \& Toh, H. (2009). Multiple alignment of DNA sequences with MAFFT. In Bioinformatics for DNA Sequence Analysis (pp. 39-64). Humana Press.

Kawai, H., Hanyuda, T., Draisma, S.G., Wilce, R.T., \& Andersen, R.A. (2015). Molecular phylogeny of two unusual brown algae, Phaeostrophion irregulare and Platysiphon glacialis, proposal of the Stschapoviales ord. nov. and Platysiphonaceae fam. nov., and a re-examination of divergence times for brown algal orders. Journal of phycology, 51(5), 918-928. https://doi.org/10.1111/jpy.12332

Kuhlenkamp, R., \& Müller, D.G. (1985). Culture studies on the life history of Haplospora globosa and Tilopteris mertensii (Tilopteridales, Phaeophyceae). British Phycological Journal, 20(4), 301-312. https://doi.org/10.1080/00071618500650311

Lehtonen, J., \& Kokko, H. (2011). Two roads to two sexes: unifying gamete competition and gamete limitation in a single model of anisogamy evolution. Behavioral Ecology and Sociobiology, 65(3), 445-459. https://doi.org/10.1007/s00265-010-1116-8

Lipinska, A.P., Cormier, A., Luthringer, R., Peters, A.F., Corre, E., Gachon, C.M., Cock, J.M., \& Coelho, S.M. (2015). Sexual dimorphism and the evolution of sex-biased gene expression in the brown alga Ectocarpus. Molecular Biology and Evolution, 32(6), 1581-1597. https://doi.org/10.1093/molbev/msv049

Lipinska, A.P., Serrano-Serrano, M.L., Cormier, A., Peters, A.F., Kogame, K., Cock, J.M., \& Coelho, S.M. (2019). Rapid turnover of life-cycle-related genes in the brown algae. Genome Biology, 20, 35. https://doi.org/10.1186/s13059-019-1630-6

This article is protected by copyright. All rights reserved 
Luthringer, R., Cormier, A., Ahmed, S., Peters, A.F., Cock, J.M., \& Coelho, S.M. (2014). Sexual dimorphism in the brown algae. Perspectives in Phycology 1(1), 11-25. https://doi.org/10.1127/2198-011X/2014/0002

Ma, Z., Gray, E., Thomas, E., Murphy, B., Zachos, J., \& Paytan, A. (2014). Carbon sequestration during the Palaeocene-Eocene Thermal Maximum by an efficient biological pump. Nature Geoscience, 7(5), 382-388. https://doi.org/10.1038/ngeo2139

Mable, B.K., \& Otto, S.P. (1998). The evolution of life cycles with haploid and diploid phases. BioEssays, 20(6), 453-462. https://doi.org/10.1002/(SICI)15211878(199806)20:6\%3C453::AID-BIES3\%3E3.0.CO;2-N

Mignerot, L., Avia, K., Luthringer, R., Lipinska, A.P., Peters, A.F., Cock, J.M., \& Coelho, S.M. (2019). A key role for sex chromosomes in the regulation of parthenogenesis in the brown alga Ectocarpus. PLoS Genetics, 15(6), e1008211. https://doi.org/10.1371/journal.pgen.1008211

Motomura, T., \& Sakai, Y. (1988). The occurrence of flagellated eggs in Laminaria angustata (Phaeophyta, Laminariales) 1. Journal of Phycology, 24(2), 282-285. https://doi.org/10.1111/j.1529-8817.1988.tb04244.x

Oppliger, L.V., Correa, J.A., \& Peters, A.F. (2007). Parthenogenesis in the brown alga Lessonia nigrescens (Laminariales, Phaeophyceae) from central Chile. Journal of Phycology, 43(6), 1295-1301. https://doi.org/10.1111/j.1529-8817.2007.00408.x

Oppliger, L.V., Von Dassow, P., Bouchemousse, S., Robuchon, M., Valero, M., Correa, J.A., Mauger, S., \& Destombe, C. (2014). Alteration of sexual reproduction and genetic diversity in the kelp species Laminaria digitata at the southern limit of its range. PLoS One, 9(7), e102518. https://doi.org/10.1371/journal.pone.0102518

Otto, S.P., \& Gerstein, A.C. (2008). The evolution of haploidy and diploidy. Current Biology, 18(24), R1121-R1124. https://doi.org/10.1016/j.cub.2008.09.039

Otto, S.P., \& Goldstein, D.B. (1992). Recombination and the evolution of diploidy. Genetics, 131(3), 745-751.

Otto, S.P., \& Marks, J.C. (1996). Mating systems and the evolutionary transition between haploidy and diploidy. Biological Journal of the Linnean Society, 57(3), 197-218. https://doi.org/10.1111/j.1095-8312.1996.tb00309.x

This article is protected by copyright. All rights reserved 
Pagel, M., Meade, A., \& Barker, D. (2004). Bayesian estimation of ancestral character states on phylogenies. Systematic Biology, 53(5), 673-684. https://doi.org/10.1080/10635150490522232

Pannell, J.R. (2017). Plant sex determination. Current Biology, 27(5), R191-R197. https://doi.org/10.1016/j.cub.2017.01.052

Paradis, E., Claude, J., \& Strimmer, K. (2004). APE: analyses of phylogenetics and evolution in $\mathrm{R} \quad$ language. $\quad$ Bioinformatics, $\quad \mathbf{2 0}(2), \quad 289-290$. https://doi.org/10.1093/bioinformatics/btg412

Parker, G.A. (1978). Selection on non-random fusion of gametes during the evolution of anisogamy. Journal of Theoretical Biology, 73(1), 1-28. https://doi.org/10.1016/00225193(78)90177-7

Parker, G.A., Baker, R.R., \& Smith, V.G.F. (1972). The origin and evolution of gamete dimorphism and the male-female phenomenon. Journal of Theoretical Biology, 36(3), 529-553. https://doi.org/10.1016/0022-5193(72)90007-0

Randerson, J.P., \& Hurst, L.D. (2001). A comparative test of a theory for the evolution of anisogamy. Proceedings of the Royal Society of London. Series B: Biological Sciences, 268(1469), 879-884. https://doi.org/10.1098/rspb.2000.1581

Rescan, M., Lenormand, T., \& Roze, D. (2016). Interactions between genetic and ecological effects on the evolution of life cycles. The American Naturalist, 187(1), 19-34. https://doi.org/10.1086/684167

Revell, L.J. (2014). Ancestral character estimation under the threshold model from quantitative genetics. Evolution, 68(3), 743-759. https://doi.org/10.1111/evo.12300

Schiel, D.R., \& Foster, M.S. (2006). The population biology of large brown seaweeds: ecological consequences of multiphase life histories in dynamic coastal environments. Annual Review of Ecology, Evolution, and Systematics, 37, 343-372. https://doi.org/10.1146/annurev.ecolsys.37.091305.110251

Schoen, D.J., \& Schultz, S.T. (2019). Somatic mutation and evolution in plants. Annual Review of Ecology, Evolution, and Systematics, 50, 49-73. https://doi.org/10.1146/annurev-ecolsys-110218-024955

This article is protected by copyright. All rights reserved 
Scott, M.F., \& Rescan, M. (2017). Evolution of haploid-diploid life cycles when haploid and diploid fitnesses are not equal. Evolution, 71(2), 215-226. https://doi.org/10.1111/evo.13125

Serrano-Serrano, M. L., Rolland, J., Clark, J. L., Salamin, N., \& Perret, M. (2017). Hummingbird pollination and the diversification of angiosperms: an old and successful association in Gesneriaceae. Proceedings of the Royal Society B: Biological Sciences, 284(1852), 20162816. https://doi.org/10.1098/rspb.2016.2816

Silberfeld, T., Leigh, J.W., Verbruggen, H., Cruaud, C., De Reviers, B., \& Rousseau, F. (2010). A multi-locus time-calibrated phylogeny of the brown algae (Heterokonta, Ochrophyta, Phaeophyceae): Investigating the evolutionary nature of the "brown algal crown radiation". Molecular Phylogenetics and Evolution, 56(2), 659-674. https://doi.org/10.1016/j.ympev.2010.04.020

Silberfeld, T., Rousseau, F., \& de Reviers, B. (2014). An updated classification of brown algae (Ochrophyta, Phaeophyceae). Cryptogamie, Algologie, 35(2), 117-156. https://doi.org/10.7872/crya.v35.iss2.2014.117

Surlyk, F., \& Sørensen, A.M. (2010). An early Campanian rocky shore at Ivö Klack, southern $\begin{array}{llll}\text { Sweden. } & \text { Cretaceous } & \text { Research, }\end{array}$ https://doi.org/10.1016/j.cretres.2010.07.006

Togashi, T., Bartelt, J.L., Yoshimura, J., Tainaka, K.I., \& Cox, P.A. (2012). Evolutionary trajectories explain the diversified evolution of isogamy and anisogamy in marine green algae. Proceedings of the National Academy of Sciences, 109(34), 1369213697. https://doi.org/10.1073/pnas.1203495109

Valero, M., Richerd, S., Perrot, V., \& Destombe, C. (1992). Evolution of alternation of haploid and diploid phases in life cycles. Trends in Ecology \& Evolution, 7(1), 25-29. https://doi.org/10.1016/0169-5347(92)90195-H

Vamosi, J.C., \& Otto, S.P. (2002). When looks can kill: the evolution of sexually dimorphic floral display and the extinction of dioecious plants. Proceedings of the Royal Society of London. Series B: Biological Sciences, 269(1496), 1187-1194. https://doi.org/10.1098/rspb.2002.2004

This article is protected by copyright. All rights reserved 
Villarreal, J.C., \& Renner, S.S. (2013). Correlates of monoicy and dioicy in hornworts, the apparent sister group to vascular plants. BMC Evolutionary Biology, 13(1), 239. https://doi.org/10.1186/1471-2148-13-239

Yu, L., Boström, C., Franzenburg, S., Bayer, T., Dagan, T., \& Reusch, T.B. (2020). Somatic genetic drift and multilevel selection in a clonal seagrass. Nature Ecology \& Evolution, 4(7), 952-962. https://doi.org/10.1038/s41559-020-1196-4 


\section{TABLES}

Table 1. Description of the traits studied, categories and discrete states. Note that some of the discrete traits were also treated as continuous traits (male gamete size for instance).

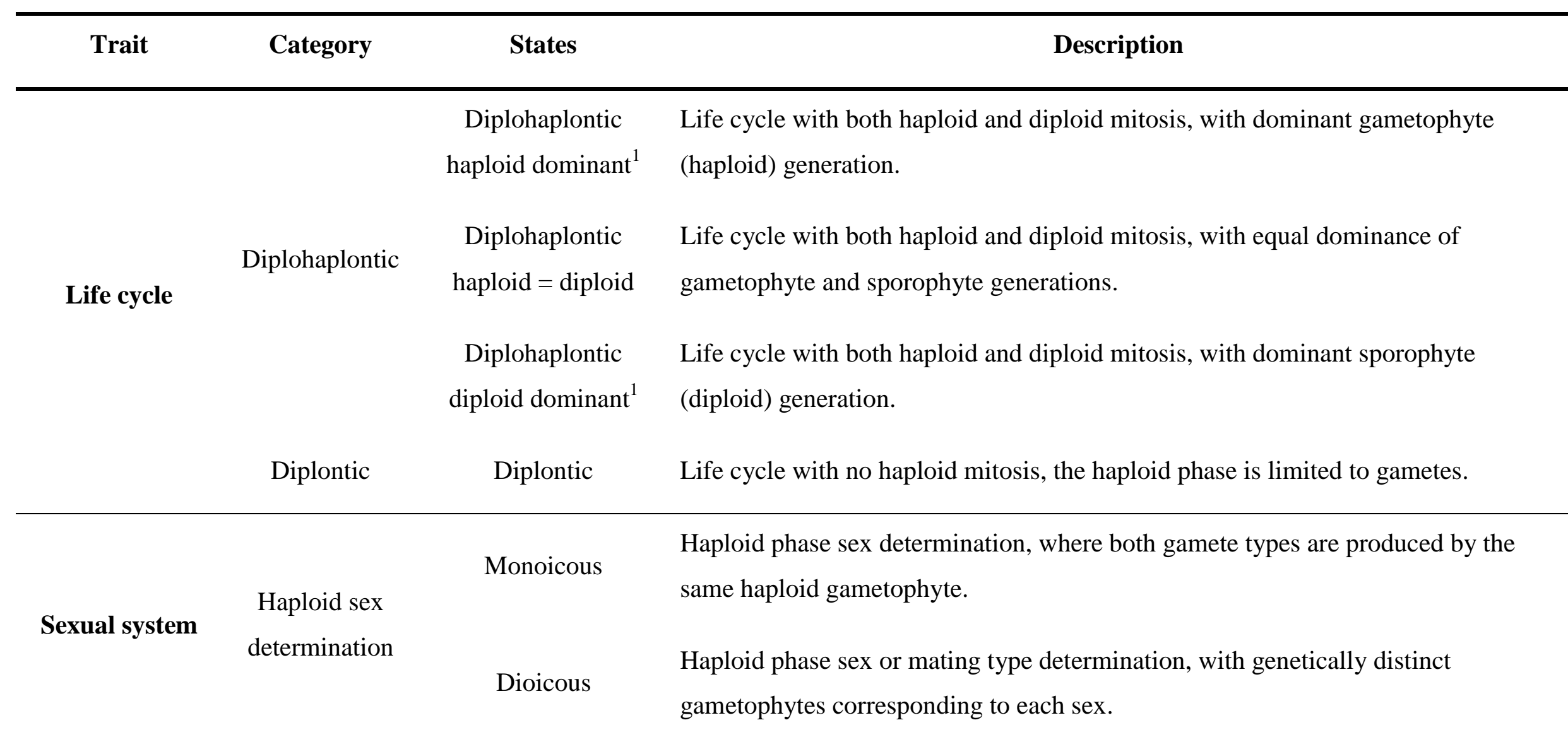

This article is protected by copyright. All rights reserved 


\begin{tabular}{|c|c|c|c|}
\hline & $\begin{array}{c}\text { Diploid sex } \\
\text { determination }\end{array}$ & Monoecious & $\begin{array}{l}\text { Diploid phase sex-determination, with genetically distinct sporophytes } \\
\text { corresponding to each sex. } \\
\text { Diploid phase sex determination, where both male and female organs are produced } \\
\text { by the same diploid sporophyte. }\end{array}$ \\
\hline \multirow{3}{*}{ Gamete size } & $\begin{array}{l}\text { Female gamete } \\
\text { with flagella }\end{array}$ & Isogamous $^{2}$ & $\begin{array}{l}\text { Male and female gametes with no noticeable size difference (but different } \\
\text { behaviour/physiology). }\end{array}$ \\
\hline & & Anisogamous & Male and female gametes of clearly different size, both with flagella. \\
\hline & $\begin{array}{l}\text { Female gamete } \\
\text { without flagella }\end{array}$ & Oogamous & Female gamete much larger and lacking a flagellum. \\
\hline \multirow[t]{2}{*}{ Parthenogenesis } & & Female gametes only & Only female gametes capable of parthenogenesis. \\
\hline & Parthenogenesis & $\begin{array}{l}\text { Male and female } \\
\text { gametes }\end{array}$ & Male and female gametes capable of parthenogenesis. \\
\hline
\end{tabular}

\footnotetext{
${ }^{1}$ The term "dominant" is defined here as the generation that presents larger size and higher complexity in terms of morphology (number of different cell types, number of tissues and organs).
}

This article is protected by copyright. All rights reserved 
${ }^{2}$ For simplicity, we code as "isogamous" algae that have almost imperceptible size differences between male and female gametes, but note that in the brown algae there is always an asymmetry (at least in terms of physiology and behaviour) between male and female gametes.

This article is protected by copyright. All rights reserved 
Table 2. List of detailed life cycle and reproductive traits across the brown algal species.

\begin{tabular}{|c|c|c|c|c|c|c|c|c|c|c|c|c|c|c|}
\hline \multirow[t]{5}{*}{ Species } & $\begin{array}{l}\text { Gamet } \\
\text { e size } \\
\text { ratio } \\
(\mathbf{F} / M)\end{array}$ & $\begin{array}{c}\text { Gamete } \\
\text { dimorphis } \\
\text { m }\end{array}$ & $\begin{array}{c}\text { Male } \\
\text { gamete } \\
\text { size (um) }\end{array}$ & $\begin{array}{c}\text { Isogamy } \\
\text { versus } \\
\text { anisogamy }\end{array}$ & $\begin{array}{l}\text { Sexual } \\
\text { system }\end{array}$ & HSD or DSD & $\begin{array}{c}\text { Co-sexual } \\
\text { versus } \\
\text { separate } \\
\text { sexes }\end{array}$ & $\begin{array}{l}\text { Type of } \\
\text { life cycle }\end{array}$ & $\begin{array}{c}\text { Generation } \\
\text { dominance } \\
\text { (simple) }\end{array}$ & $\begin{array}{l}\text { Generation } \\
\text { dominance }\end{array}$ & $\begin{array}{c}\text { Parthenoge } \\
\text { nesis } \\
\text { capacity }\end{array}$ & $\begin{array}{c}\text { Both } \\
\text { partenog } \\
\text { enesis }\end{array}$ & $\begin{array}{c}\text { Parthenoge } \\
\text { nesis } \\
\text { presence/a } \\
\text { bsence }\end{array}$ & $\begin{array}{c}\text { Male } \\
\text { parthenoge } \\
\text { nesis }\end{array}$ \\
\hline & & $\begin{array}{l}0= \\
\text { isogamous }\end{array}$ & & $\begin{array}{l}0= \\
\text { isogamous }\end{array}$ & $\begin{array}{l}0= \\
\text { monoicou } \\
\mathrm{s}\end{array}$ & $\begin{array}{l}0=\text { haploid } \\
\text { sex } \\
\text { determination }\end{array}$ & $\begin{array}{l}0=\text { sexes } \\
\text { on same } \\
\text { thallus }\end{array}$ & $\begin{array}{l}0=H / D \\
\text { with } H>D\end{array}$ & $\begin{array}{l}0=\text { haploid } \\
\text { dominant (or } \\
\text { similar } \\
\text { dominance) }\end{array}$ & $0=\mathrm{H}>>\mathrm{D}$ & $\begin{array}{l}0=\text { no } \\
\text { partenogene } \\
\text { sis }\end{array}$ & $\begin{array}{l}0=\text { none } \\
\text { or } 1 \mathrm{do}\end{array}$ & $\begin{array}{l}0=\text { no } \\
\text { partenogene } \\
\text { sis }\end{array}$ & $\begin{array}{l}0=\text { no male } \\
\text { parthenoge } \\
\text { nesis }\end{array}$ \\
\hline & & $\begin{array}{l}1= \\
\text { anisogamou } \\
\mathrm{s}\end{array}$ & & $\begin{array}{l}1= \\
\text { anisogamou } \\
\text { s and } \\
\text { oogamous }\end{array}$ & $\begin{array}{l}1= \\
\text { dioicous }\end{array}$ & $\begin{array}{l}1=\text { diploid } \\
\text { sex } \\
\text { determination }\end{array}$ & $\begin{array}{l}1=\text { sexes } \\
\text { on separate } \\
\text { thalli }\end{array}$ & $\begin{array}{l}1=\mathrm{H} / \mathrm{D} \\
\text { with } \mathrm{H}=\mathrm{D}\end{array}$ & $\begin{array}{l}1 \text { = diploid } \\
\text { dominant }\end{array}$ & $1=\mathrm{H}=\mathrm{D}$ & $\begin{array}{l}1 \text { = female } \\
\text { only }\end{array}$ & $\begin{array}{l}1 \text { = both } \\
\text { do } \\
\text { partenoge } \\
\text { nesis }\end{array}$ & $\begin{array}{l}1=\text { at least } \\
\text { female does }\end{array}$ & $\begin{array}{l}1=\text { male } \\
\text { parthenoge } \\
\text { nesis }\end{array}$ \\
\hline & & $\begin{array}{l}2= \\
\text { oogamous }\end{array}$ & & & $\begin{array}{l}2= \\
\text { monoecio } \\
\text { us }\end{array}$ & & & $\begin{array}{l}2=\mathrm{H} / \mathrm{D} \\
\text { with } \mathrm{D}>\mathrm{H}\end{array}$ & & $2=\mathrm{D} \gg>\mathrm{H}$ & $\begin{array}{l}2=\text { female } \\
\text { and male }\end{array}$ & & & \\
\hline & & & & & $\begin{array}{l}3= \\
\text { dioecious }\end{array}$ & & & $\begin{array}{l}3= \\
\text { Diploid }\end{array}$ & & $\begin{array}{l}3 \text { = Diplont } \\
\text { (no H) }\end{array}$ & & & & \\
\hline Bifurcaria bifurcata & NA & 2 & NA & 1 & 2 & 1 & 0 & 3 & 1 & 3 & NA & NA & NA & NA \\
\hline Cystoseira tamariscifolia & NA & 2 & NA & 1 & 2 & 1 & 0 & 3 & 1 & 3 & NA & NA & NA & NA \\
\hline Cystoseira baccata & 26 & 2 & 4 & 1 & 2 & 1 & 0 & 3 & 1 & 3 & NA & NA & NA & NA \\
\hline Cystoseira nodicaulis & 26 & 2 & 4 & 1 & 2 & 1 & 0 & 3 & 1 & 3 & NA & NA & NA & NA \\
\hline Cystophora grevillei & 26 & 2 & 4 & 1 & 2 & 1 & 0 & 3 & 1 & 3 & NA & NA & NA & NA \\
\hline Cystophora retorta & 26 & 2 & 4 & 1 & 2 & 1 & 0 & 3 & 1 & 3 & NA & NA & NA & NA \\
\hline Halidrys siliquosa & NA & 2 & NA & 1 & 2 & 1 & 0 & 3 & 1 & 3 & NA & NA & NA & NA \\
\hline Sargassum fallax & NA & 2 & NA & 1 & 2 & 1 & 0 & 3 & 1 & 3 & NA & NA & NA & NA \\
\hline Sargassum muticum & NA & 2 & NA & 1 & 2 & 1 & 0 & 3 & 1 & 3 & NA & NA & NA & NA \\
\hline Caulocystis cephalornithos & NA & 2 & NA & 1 & 2 & 1 & 0 & 3 & 1 & 3 & NA & NA & NA & NA \\
\hline Caulocystis uvifera & NA & 2 & NA & 1 & 2 & 1 & 0 & 3 & 1 & 3 & NA & NA & NA & NA \\
\hline
\end{tabular}

This article is protected by copyright. All rights reserved 


\begin{tabular}{cc} 
NA & 2 \\
NA & 2 \\
12,4 & 2 \\
NA & 2 \\
NA & 2 \\
NA & 2 \\
26 & 2 \\
26 & 2 \\
26 & 2 \\
2 & 1 \\
2,3 & 1 \\
5,2 & 1 \\
4,7 & 1 \\
7,5 & 2 \\
NA & 2 \\
NA & 2 \\
5,6 & 2 \\
1,2 & 1 \\
NA & NA \\
1 & 0 \\
7,8 & 2 \\
2,9 & 2 \\
3 & 2 \\
NA & 2 \\
NA & 2 \\
3,6 & 1 \\
NA & 2 \\
NA & 2 \\
NA & 2 \\
\hline
\end{tabular}

\begin{tabular}{|c|c|c|}
\hline NA & 1 & 3 \\
\hline NA & 1 & 2 \\
\hline 3 & 1 & 3 \\
\hline NA & 1 & 3 \\
\hline NA & 1 & 2 \\
\hline NA & 1 & 3 \\
\hline 4 & 1 & 3 \\
\hline 4 & 1 & 3 \\
\hline 4 & 1 & 2 \\
\hline 5 & 1 & 2 \\
\hline 7 & 1 & 0 \\
\hline 5 & 1 & 1 \\
\hline 5 & 1 & 0 \\
\hline 8 & 1 & 2 \\
\hline NA & 1 & 1 \\
\hline NA & 1 & 1 \\
\hline 6 & 1 & 0 \\
\hline 7 & 1 & 1 \\
\hline NA & NA & NA \\
\hline 8 & 0 & 2 \\
\hline 5 & 1 & 1 \\
\hline 8 & 1 & 1 \\
\hline 8 & 1 & 1 \\
\hline NA & 1 & 1 \\
\hline NA & 1 & 1 \\
\hline 9 & 1 & 1 \\
\hline 8 & 1 & 1 \\
\hline NA & 1 & 1 \\
\hline NA & 1 & 1 \\
\hline
\end{tabular}

1
1
1
1
1
1
1
1
1
1
0
0
0
1
0
0
0
0
0
0
0
0
0
0
0
0
0
0
0
0
0
0
0
0
0
0
0
0
0
0
0
0
0
0
0
0
0
0
0
0
0
0
0
0
0
0
0
0
0
0
0
0
0
0
0
0
0
0

This article is protected by copyright. All rights reserved 
Hydroclathrus clathratus

Rosenvingea intricata

Chnoospora implexa

Colpomenia peregrina

Petalonia fascia

Scytosiphon lomentaria

Ectocarpus sp.

Petrospongium berkeleyi

Feldmannia mitchelliae

Pylaiella littoralis

Elachista fucicola

Chordaria linearis

Dictyosiphon foeniculaceus

Striaria attenuata

Asterocladon interjectum

Scytothamnus australis

Splachnidium rugosum

Bachelotia antillarum

Carpomitra costata

Perithalia caudata

Bellotia eriophorum

Sporochnus pedunculatus

Arthrocladia villosa

Desmarestia menziesii

Himantothallus

grandifolius

Desmarestia aculeata

Desmarestia ligulata

Desmarestia viridis

Cladostephus spongiosus

\begin{tabular}{cc} 
NA & 0 \\
NA & 0 \\
1 & 0 \\
1,5 & 1 \\
1 & 0 \\
1,1 & 0 \\
NA & 1 \\
NA & NA \\
1,7 & 1 \\
1 & 0 \\
NA & NA \\
NA & 0 \\
1 & 0 \\
1 & 0 \\
NA & 1 \\
1 & 0 \\
1,75 & 1 \\
NA & NA \\
5,5 & 2 \\
2,9 & 2 \\
NA & 2 \\
7,5 & 2 \\
2,1 & 2 \\
2,3 & 2 \\
5 & 2 \\
6 & 2 \\
NA & 2 \\
3,9 & 2 \\
1 & 0 \\
\hline
\end{tabular}

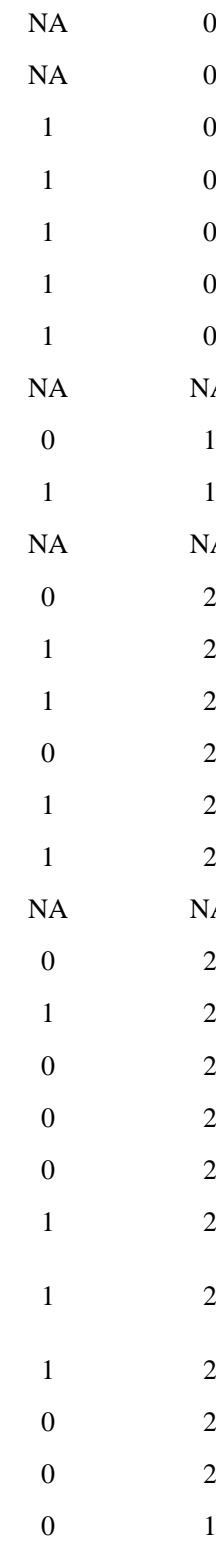

\begin{tabular}{|c|c|c|c|}
\hline NA & NA & NA & NA \\
\hline NA & NA & NA & NA \\
\hline NA & NA & NA & NA \\
\hline 1 & 0 & 1 & 0 \\
\hline 2 & 1 & 1 & 1 \\
\hline 2 & 1 & 1 & 1 \\
\hline 2 & 1 & 1 & 1 \\
\hline NA & NA & NA & NA \\
\hline 1 & 0 & 1 & 0 \\
\hline NA & NA & NA & NA \\
\hline NA & NA & NA & NA \\
\hline NA & NA & NA & NA \\
\hline 2 & 1 & 1 & 1 \\
\hline 2 & 1 & 1 & 1 \\
\hline NA & NA & NA & NA \\
\hline 2 & 1 & 1 & 1 \\
\hline 1 & 0 & 1 & 0 \\
\hline NA & NA & NA & NA \\
\hline NA & NA & NA & NA \\
\hline 2 & 1 & 1 & 1 \\
\hline NA & NA & NA & NA \\
\hline NA & NA & NA & NA \\
\hline NA & NA & NA & NA \\
\hline 0 & 0 & 0 & 0 \\
\hline 0 & 0 & 0 & 0 \\
\hline 1 & 0 & 1 & 0 \\
\hline NA & NA & NA & NA \\
\hline NA & NA & NA & NA \\
\hline
\end{tabular}

This article is protected by copyright. All rights reserved 
Syringoderma phinneyi

Padina spp

Dictyopteris polypodioides

Dictyota dichotoma

Ishige okamurae

Phaeosiphoniella cryophila

Schizocladia ischiensis

Vaucheria litorea

$\mathrm{H}=$ haploid; $\mathrm{D}=$ diploid; outgroup indicated in bold.

\begin{tabular}{cccccccc}
1 & 2 & 1 & 2 & 2 & 1 & 1 & 1 \\
1 & 1 & 0 & 1 & 0 & 0 & 0 & 0 \\
1 & 1 & 0 & 1 & 0 & 0 & 0 & 0 \\
1 & 1 & 0 & 1 & 0 & 0 & 0 & 0 \\
NA & NA & NA & NA & NA & NA & NA & NA \\
NA & NA & NA & NA & NA & NA & NA & NA \\
NA & NA & NA & NA & NA & NA & NA & NA \\
$\mathbf{1}$ & $\mathbf{3}$ & $\mathbf{1}$ & $\mathbf{3}$ & $\mathbf{0}$ & $\mathbf{0}$ & $\mathbf{0}$ & $\mathbf{0}$ \\
\hline
\end{tabular}

3

$\begin{array}{ll}1 & 0 \\ 1 & 0 \\ 1 & 0 \\ 1 & 0 \\ \text { NA } & 0 \\ \text { NA } & 0 \\ \text { NA } & \mathbf{0} \\ \mathbf{3} & \mathbf{1}\end{array}$

.

This article is protected by copyright. All rights reserved 


\section{SUPPLEMENTAL TABLES}

Table S1: Accession number for the sequences of the species that were not included in (Silberfeld et al. 2010).

Table S2. Analysis of the ancestral states for each studied trait.

Table S3. Analysis of correlations between traits.

\section{SUPPLEMENTAL DATASETS}

Supplementary Dataset 1: Details of all the traits and species used in this work, including references.

Supplementary Dataset 2: Nexus file containing the partitioned multiple sequence alignment and the common ancestor tree retrieved from BEAST. 


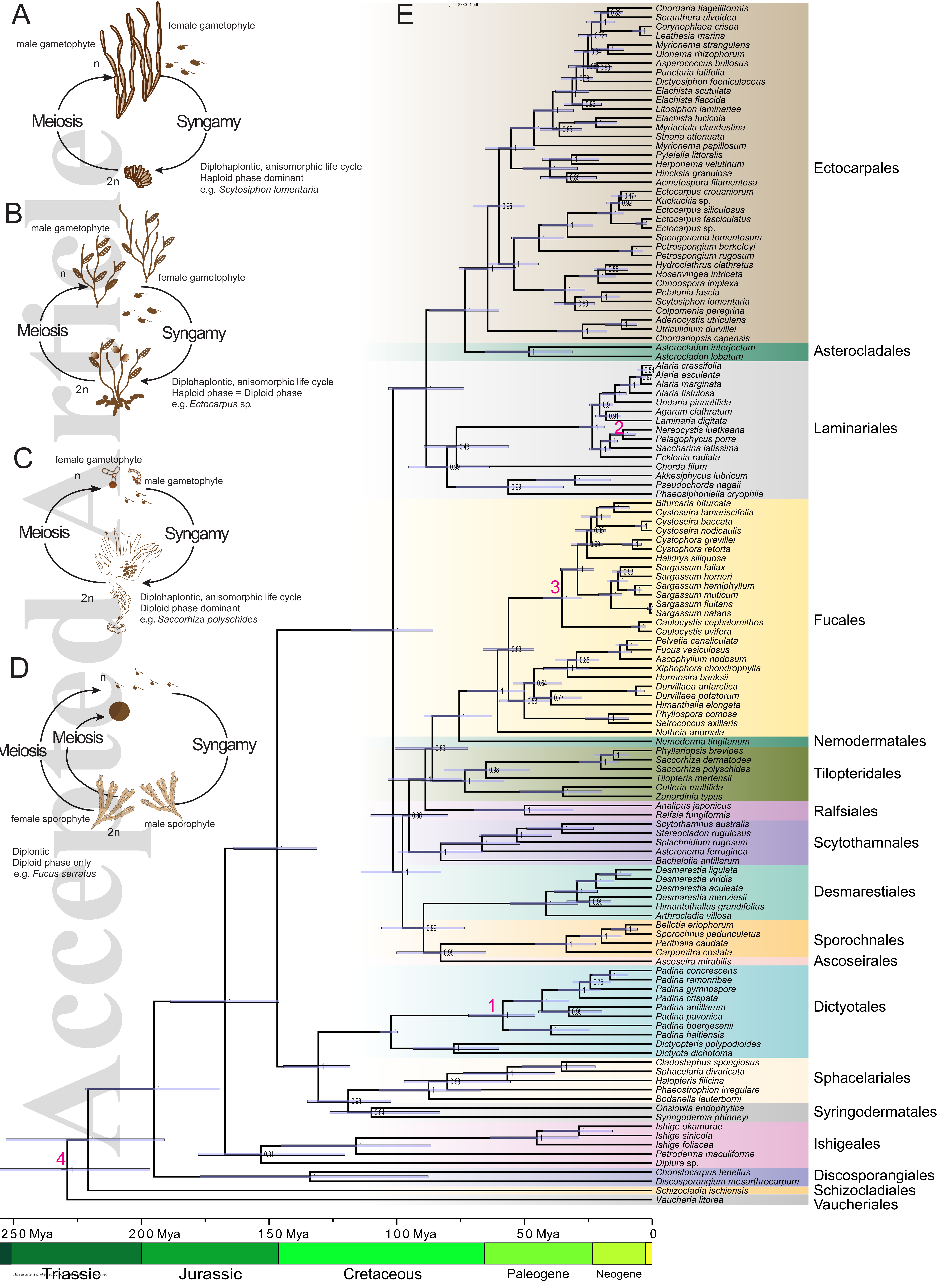




\section{A}

Life cycle

- Haploid >>Diploid

- Haploid = Diploid

- Diploid >> Haploid

- Only diploid

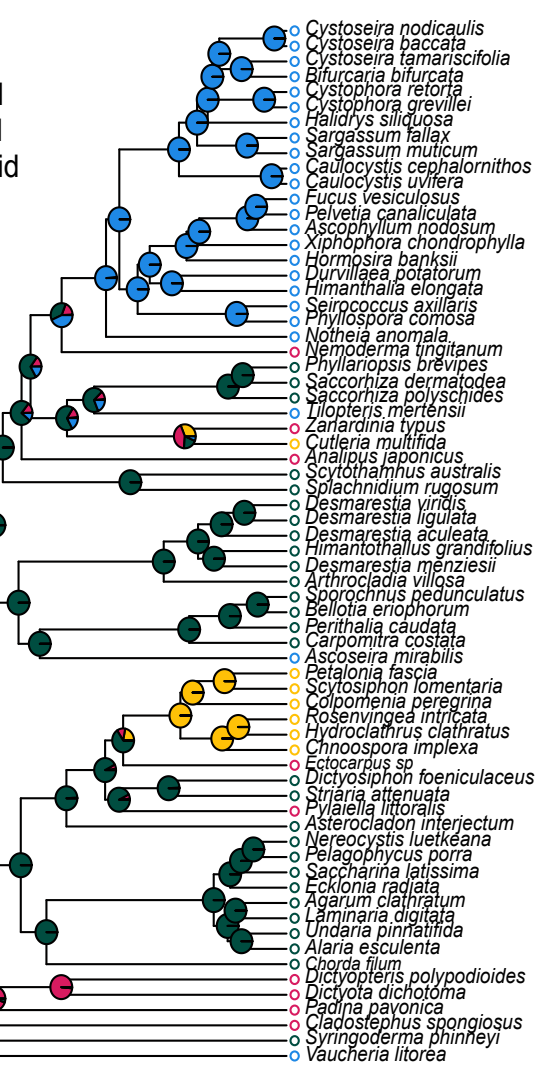

C

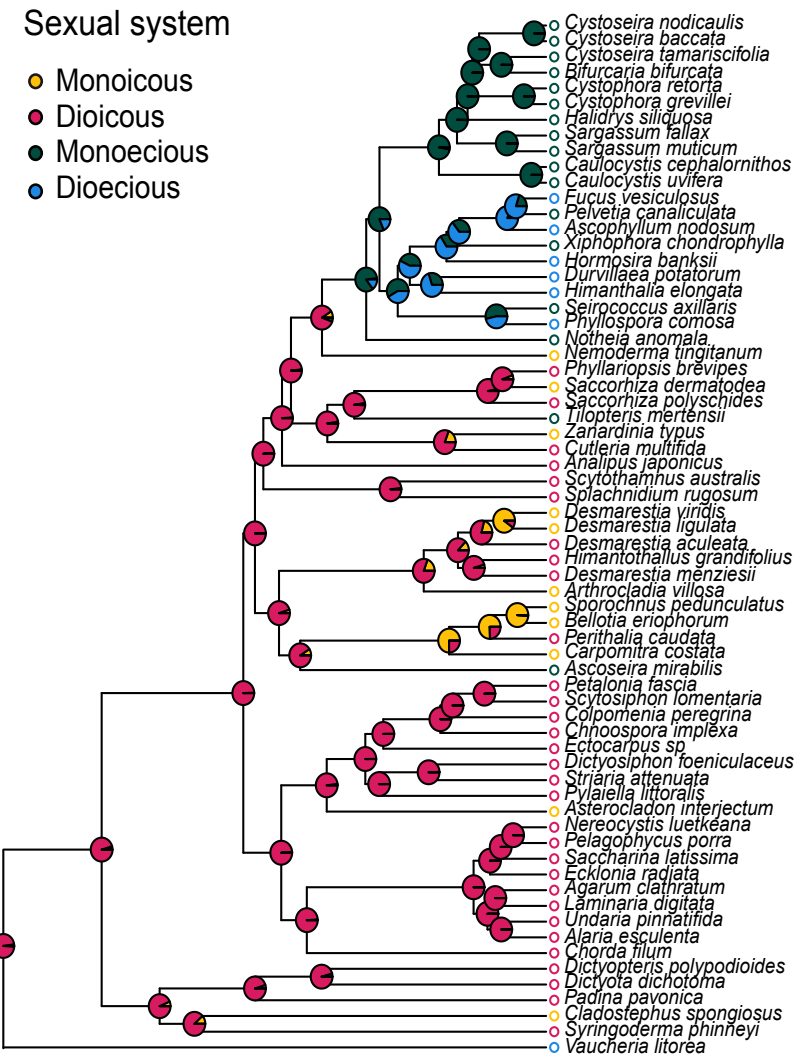

B

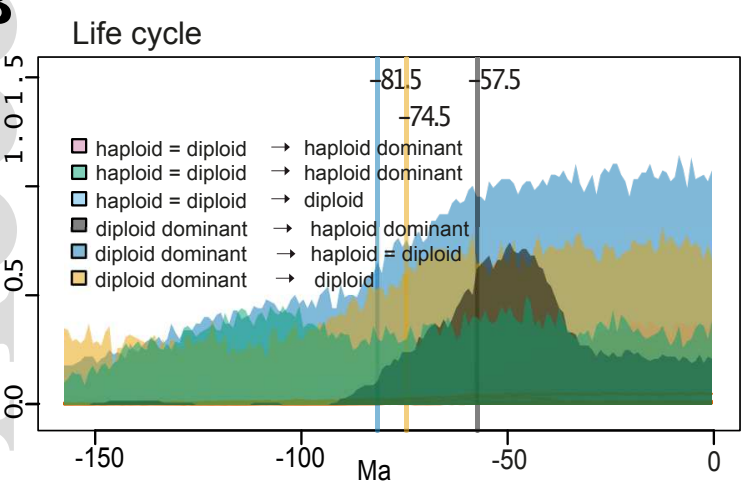

D

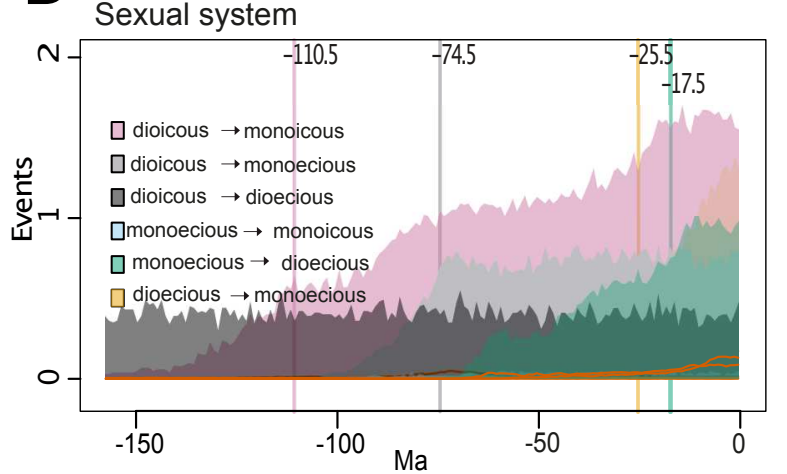

E

Male/Female gamete size

- Isogamy

- Anisogamy
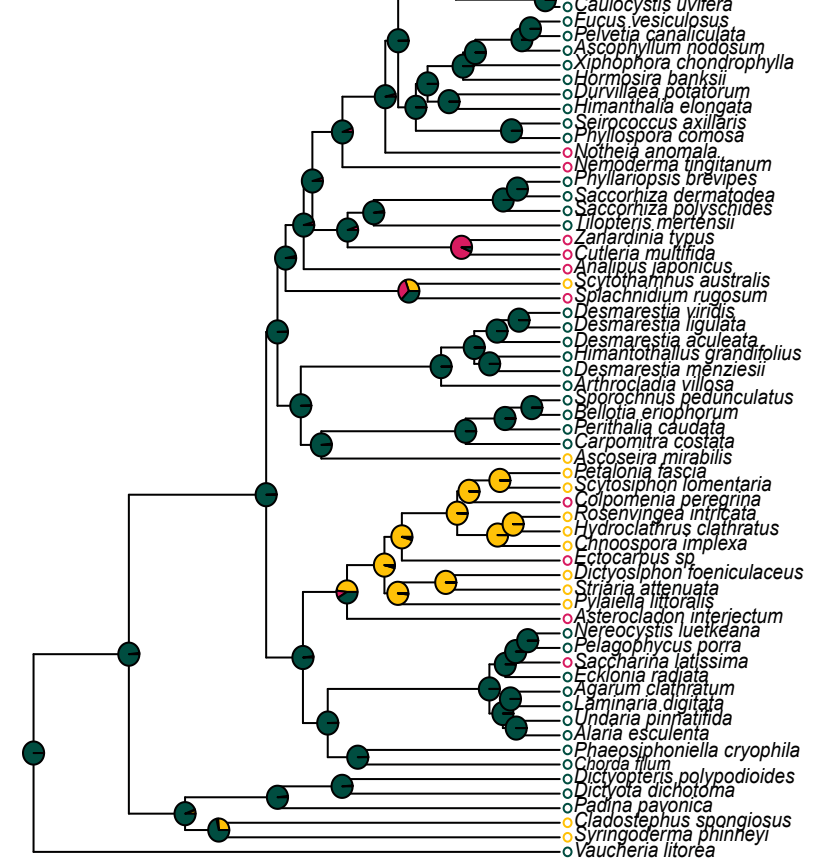

$\mathbf{F}$

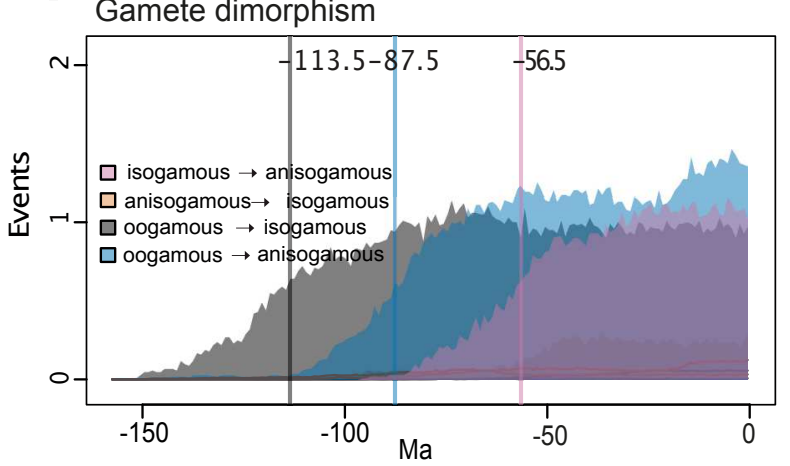

G

Partenogenesis

○ No parthenogenesis

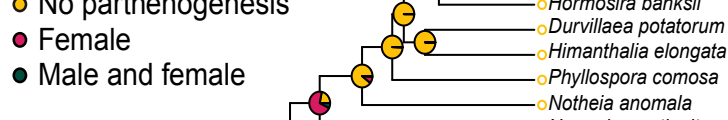

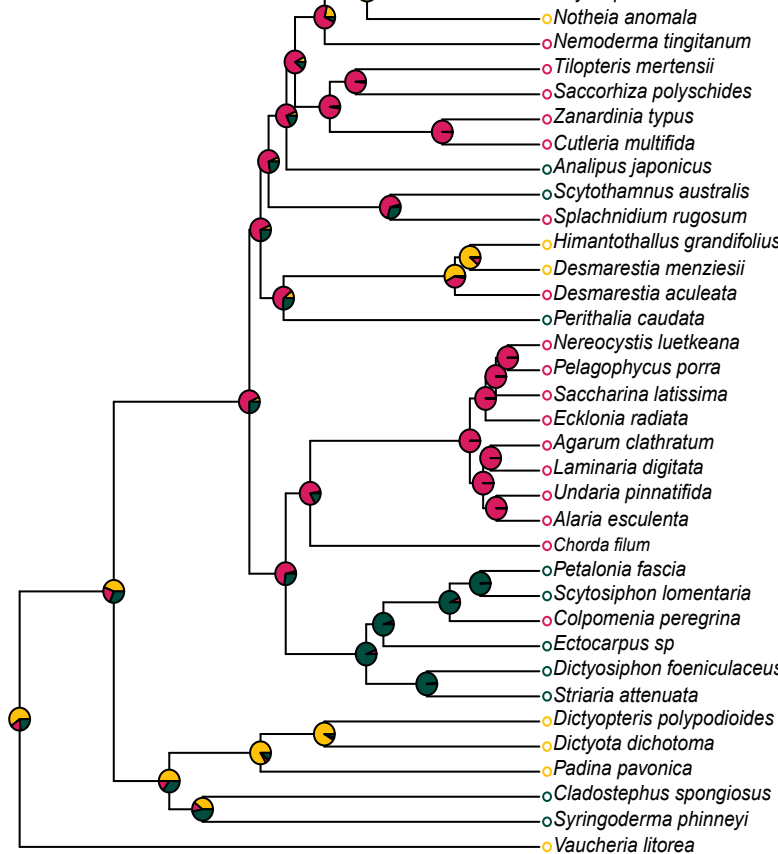

H

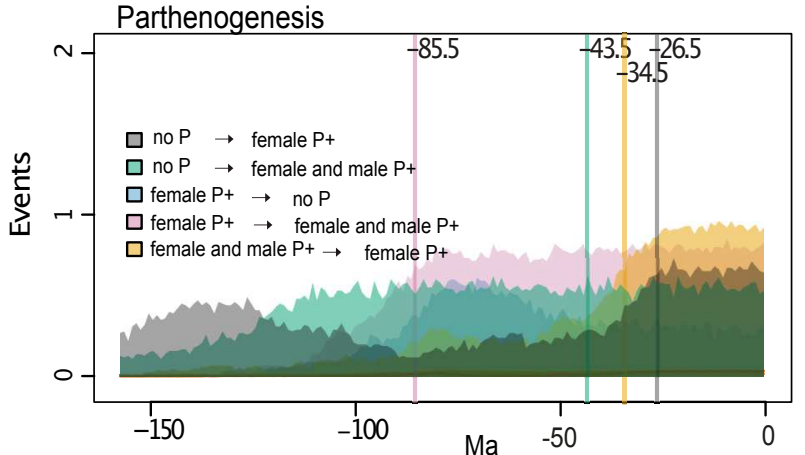

This article is protected by copyright. All rights reserved 
jeb_13880_f3.pdf

Correlation between sexual system and life cycle dominance

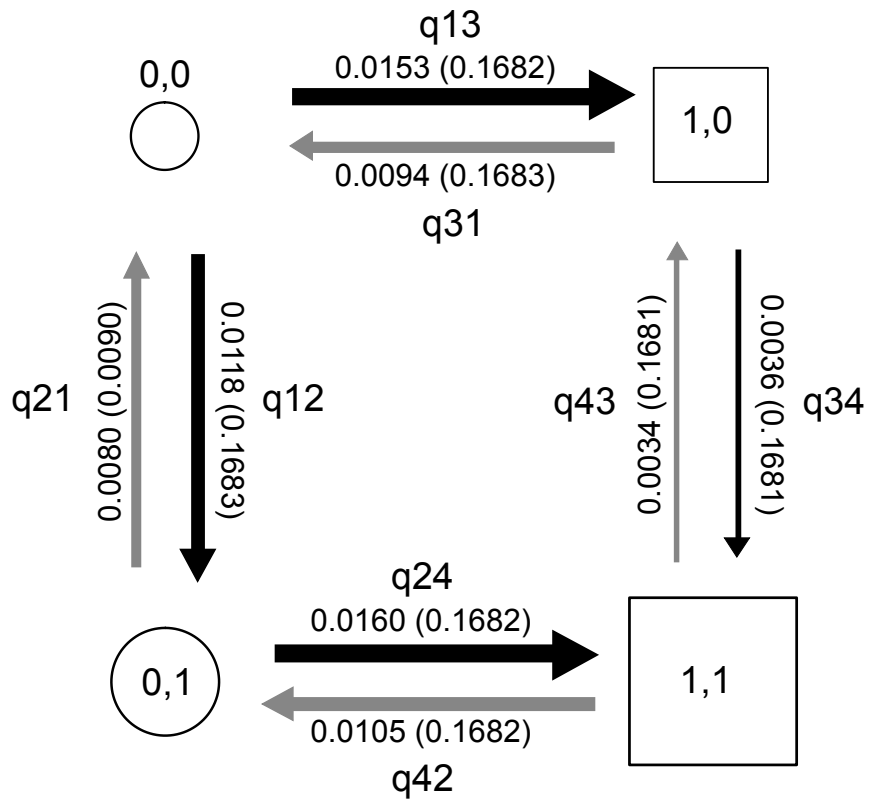

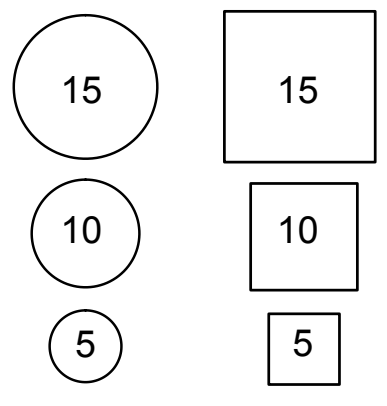

Size

0,0 : monoicous, haploid dominant

0,1 : monoicous, diploid dominant

1,0 : dioicous, haploid dominant

1,1 : dioicous, diploid dominant 


\section{jeb_13880_f4.pdf}

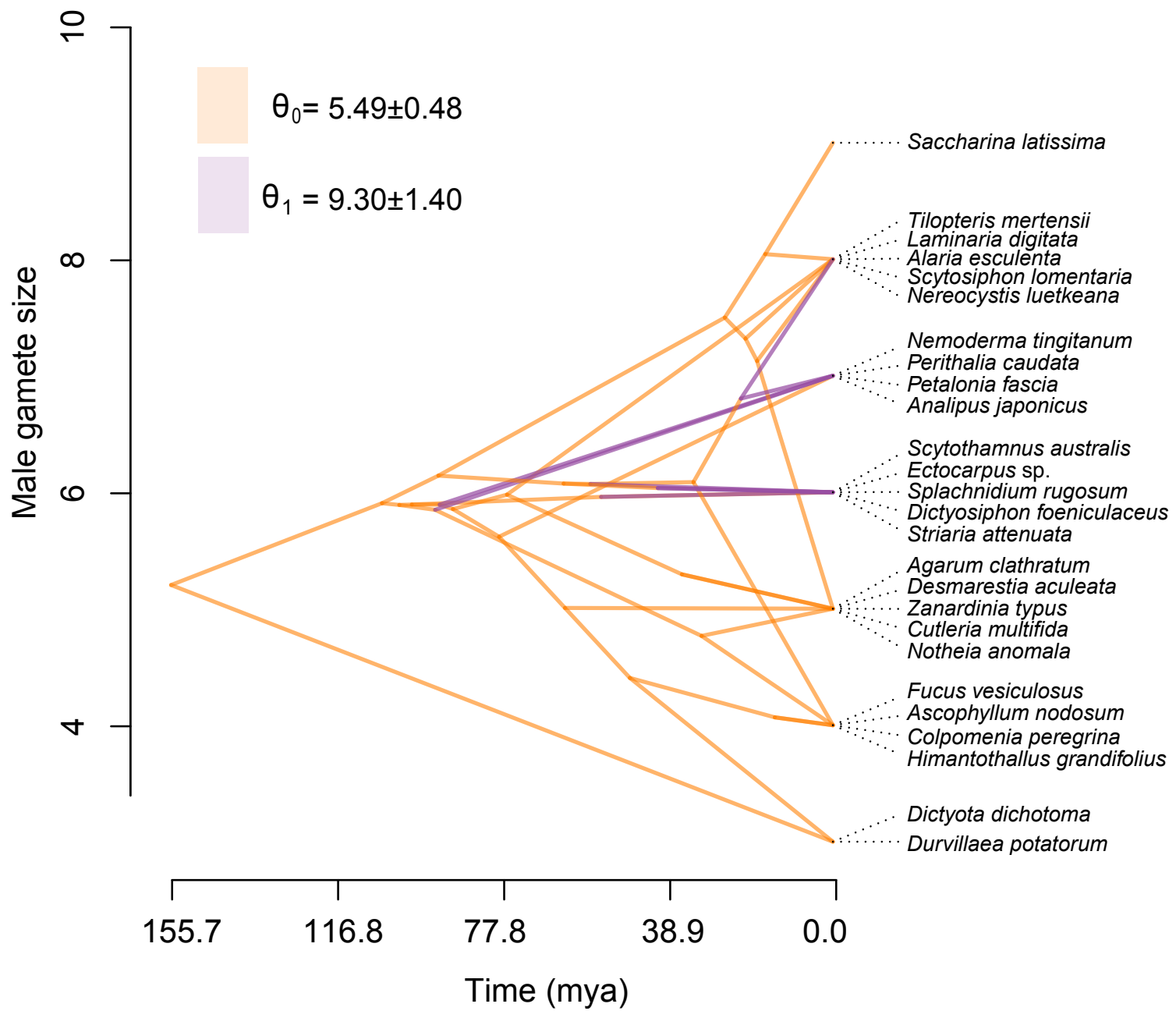

